\title{
Identity and Self -Efficacy Development of Adolescents in an Adult Sponsored Volunteer Program
}

\author{
Amanda Webster \\ West Virginia University
}

Follow this and additional works at: https://researchrepository.wvu.edu/etd

\section{Recommended Citation}

Webster, Amanda, "Identity and Self -Efficacy Development of Adolescents in an Adult Sponsored Volunteer Program" (2011). Graduate Theses, Dissertations, and Problem Reports. 828.

https://researchrepository.wvu.edu/etd/828

This Thesis is protected by copyright and/or related rights. It has been brought to you by the The Research Repository @ WVU with permission from the rights-holder(s). You are free to use this Thesis in any way that is permitted by the copyright and related rights legislation that applies to your use. For other uses you must obtain permission from the rights-holder(s) directly, unless additional rights are indicated by a Creative Commons license in the record and/ or on the work itself. This Thesis has been accepted for inclusion in WVU Graduate Theses, Dissertations, and Problem Reports collection by an authorized administrator of The Research Repository @ WVU. For more information, please contact researchrepository@mail.wvu.edu. 
Identity and Self -Efficacy Development of Adolescents in an Adult Sponsored Volunteer

Program

Amanda Webster

Thesis submitted to the

College of Human Resources and Education

at West Virginia University

in partial fulfillment of the requirements for the degree of

Master of Arts

In Educational Psychology

With an emphasis in Child Development and Family Studies

Carol Markstrom, Ph.D., Committee Chairperson

Jessica Troilo, Ph.D., Member

Nancy Wolfe-Dilgard, Member

Department of Technology, Learning, and Culture

Morgantown, West Virginia

2011

Keywords: Adolescents; Identity; Fidelity; Self-efficacy

Copyright 2011 Amanda J. Webster 


\begin{abstract}
Identity and Self -Efficacy Development of Adolescents in an Adult Sponsored Volunteer Program
\end{abstract}

\title{
Amanda Webster
}

The purpose of this study was to fill a current gap in the literature on the impacts of adolescents' participation in adult sponsored volunteer programs on identity formation and self-efficacy. Data were collected from 28 adolescents in grades 7-12 enrolled in an 11-week summer adult sponsored volunteer program. Participants completed pre-and posttest measures that included the Identity Style Inventory-Grade 6 (ISI-6G), the fidelity subscale of the Psychosocial Inventory of Ego Strength (PIES), and the General Self-Efficacy Scale. The current study proposed five hypotheses: (1) adolescents who participate in an adult sponsored volunteer program will have higher levels of the informational style of identity posttest compared to pretest; (2) adolescents who participate in an adult sponsored volunteer program will have lower levels of normative and diffuse/ avoidant identity styles posttest compared to pretest; (3) adolescents who participate in an adult sponsored volunteer program will have higher levels of commitment posttest compared to pretest; (4) adolescents who participate in an adult sponsored volunteer program will have higher levels of the ego strength of fidelity posttest compared to pretest ; and (5) adolescents who participate in an adult sponsored volunteer program will have higher levels of self-efficacy posttest compared to pretest. The results indicated significant findings for identity orientation, commitment, fidelity, and self-efficacy supporting hypothesis $1,3,4$, and 5; whereas, hypothesis 2 was found to be non-significant. Additionally, the reliability of the measures assured accurate assessment of the measures. These findings make it plausible that adult sponsored volunteer programs support positive identity development and increased self-efficacy of adolescents. 


\section{ACKNOWLEDGMENTS}

First and foremost I would like to thank my family, boyfriend, friends, and co-workers for their unwavering support through this process. I also want to extend a special thanks to my parents and grandparents who always expressed the importance of education and sticking to your goals. Additionally, this process would not have been possible without my thesis committee, especially the insightful advice and patient encouragement of Dr. Carol Markstrom for whom this process would not have been possible. 


\section{TABLE OF CONTENTS}

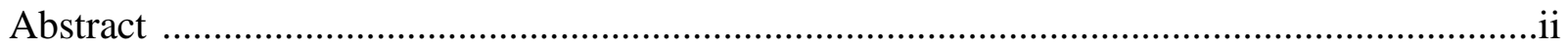

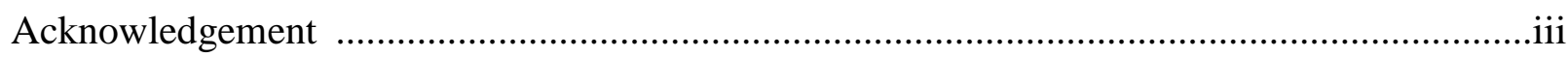

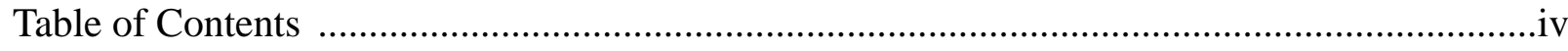

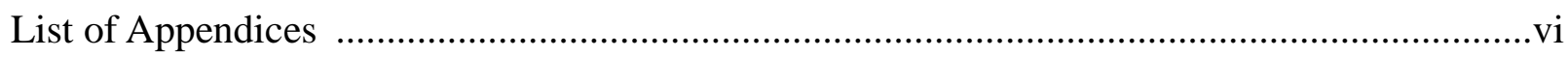

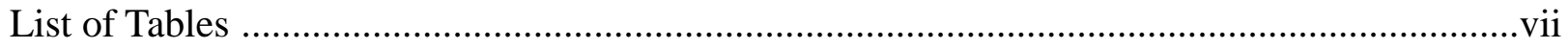

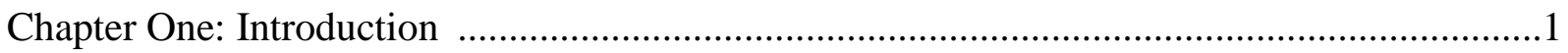

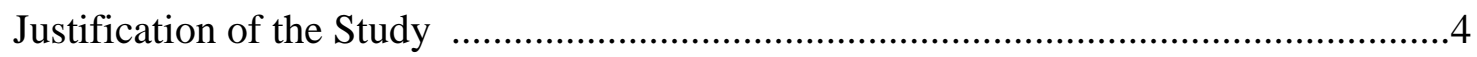

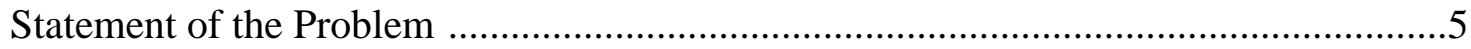

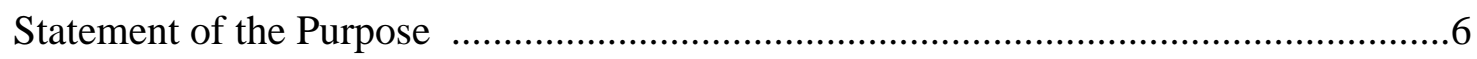

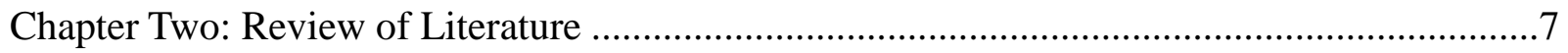

Adult Sponsored Youth Structured Activities .....................................................

Adolescent Volunteerism .......................................................................

Theoretical Framework ................................................................................

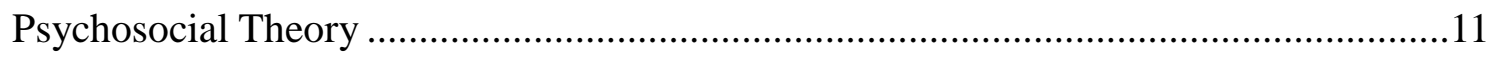

Identity and the Ego Strength of Fidelity ......................................................... 12

Social Cognitive Theory: Self-Efficacy ........................................................... 14

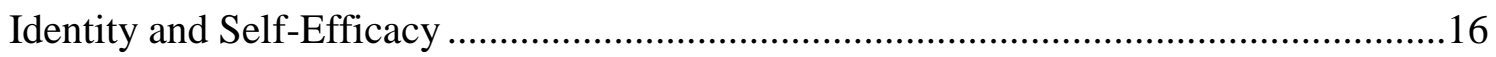

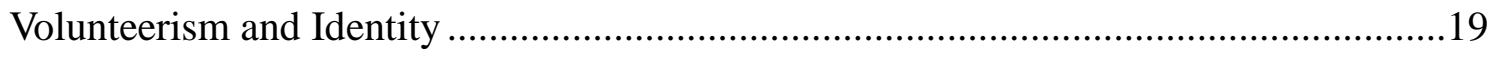

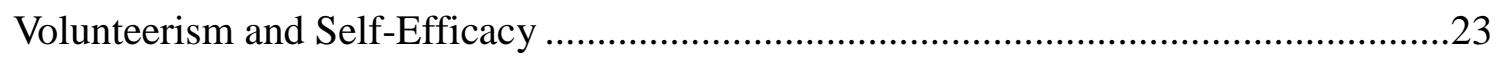

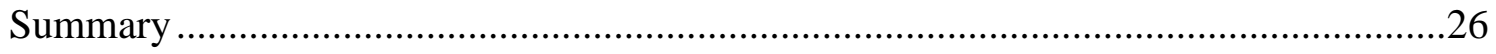

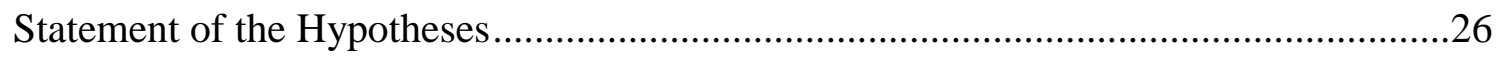

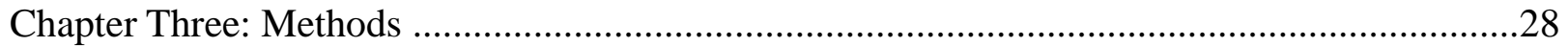




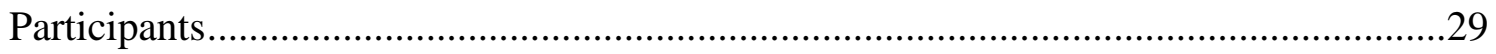

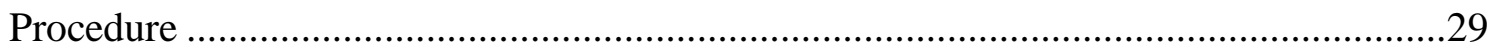

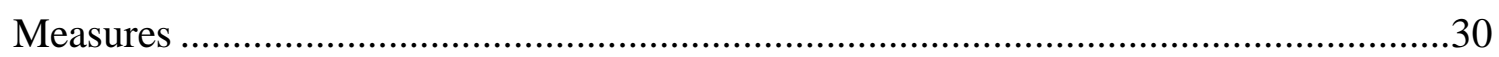

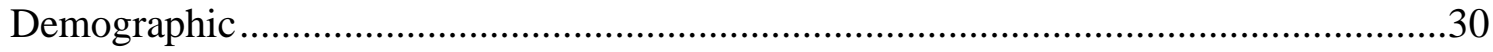

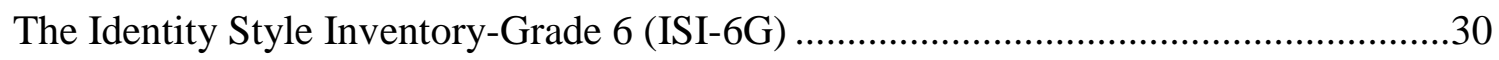

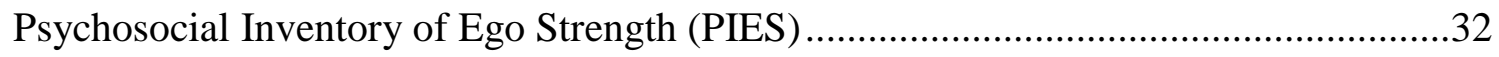

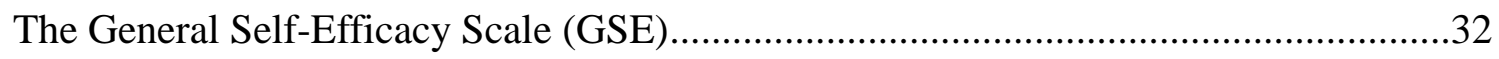

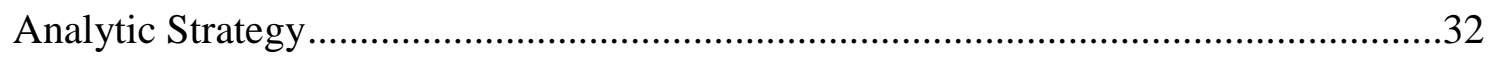

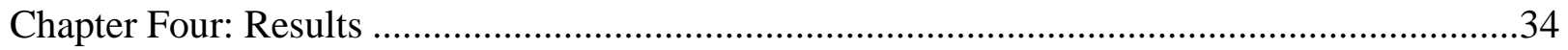

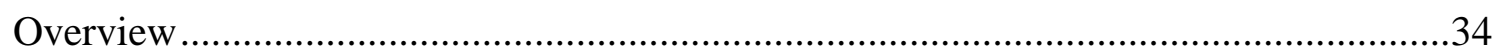

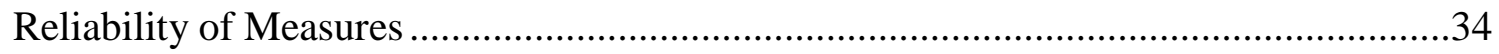

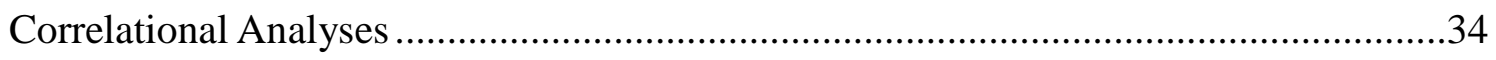

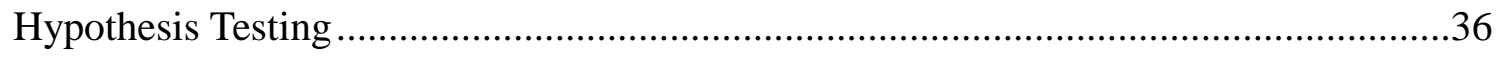

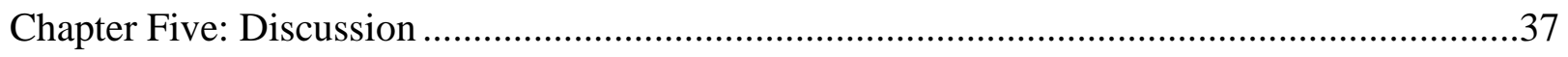

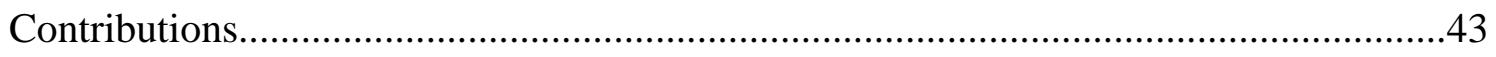

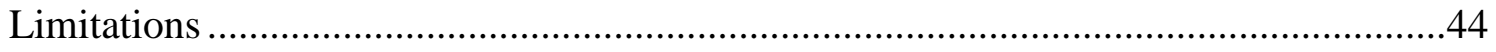

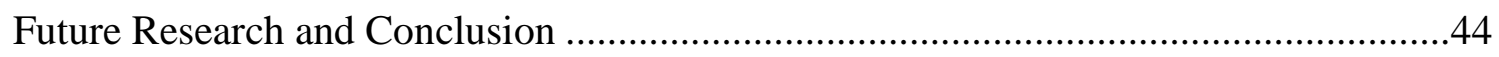

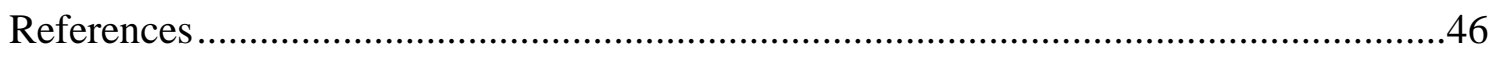

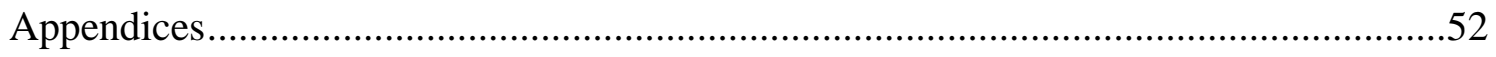




\section{Appendices}

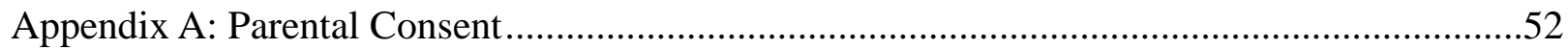

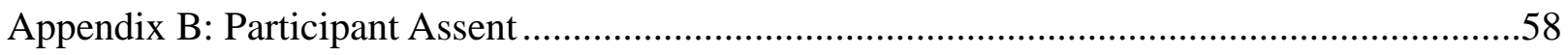

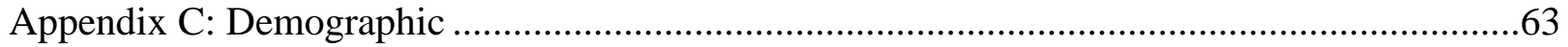

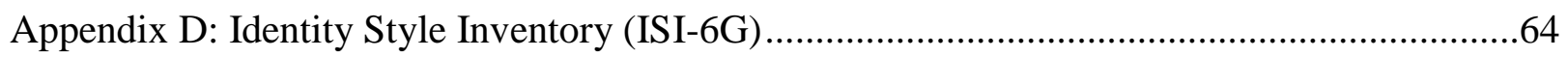

Appendix E: Psychosocial Inventory of Ego Strength (PIES) .........................................71

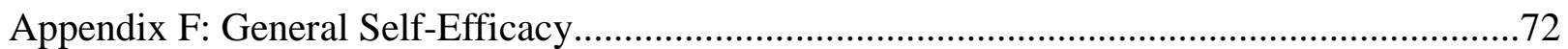




\section{List of Tables}

Table 1- Cronbach's alphas for ISI-6G subscales, PIES fidelity subscale, and GSE .................73

Table 2- Summary of Pretest Intercorrelations of Measures .................................................74

Table 3- Summary of Posttest Intercorrelations of Measures ................................................75

Table 4- T-tests, Means, and Standard Deviation Statistics................................................76 
Running Head: IDENTITY AND SELF-EFFICACY DEVELOPMENT 1

\section{Chapter 1}

\section{Introduction}

Adolescence is a transitional phase between childhood and adulthood. It is a stage in which patterns of decision making emerge for fulfillment of short term and long term goals. These decisions are part of what begin to shape adolescents and make them into their own unique individuals. The newly established and emerging identity involves distancing from a parentbased support system and moving towards a peer-based support system (Erikson, 1968). Both sets of relationships are important to the growth and function of the adolescent. Additionally, this stage encompasses the onset of sudden and often rapid changes in physical, cognitive, and socioemotional development (Erikson, 1968). This transition is often accompanied by some degree of self-consciousness. Nonetheless, an increase in cognitive capabilities produces thought- provoking ideas and opinions that can challenge and or strengthen parental, familial, peer, and community relationships (Markstrom, Li, \& Wilfong, 2005). Adolescents face the challenge of manifesting their passionate ideas and opinions in negative or positive contexts and forming the relationships that are entailed in this dynamic all of which are occurring while they are grasping the challenges of their own developing and emerging identity. Additionally, the mechanisms that occur within these contexts can support identity development. One such mechanism is the construct of self-efficacy, which can broaden the extent to which an adolescent will pursue interests and goals, which fulfill the needs for role resolution and identity development (Bandura, 2006). Further research can expand on the commonalities of these three variables: self-efficacy, participation in adult sponsored volunteer activities, and identity achievement. The potential association between these variables is essential to the expansion of this research and ultimately implemented within adult sponsored volunteer activities to encourage positive adolescent development. 
As adolescents put their ideas into action, their efforts and development are greatly enhanced by encouragement, skill building, and the chance to reflect on their experiences (Benson, Scales, Hamilton, \& Sesma, 2007). A positive outlet for these experiences can lend to a more effective resolution of the identity crisis. Through experiences that give meaning and direction to adolescents, the identity process is supported. However, through the process of seeking their identity many new freedoms are granted and many of those experiences entail risk behaviors. Adolescence is the peak period for experimentation with alcohol, smoking, sex, and other high risk behaviors (D’Amico \& McCarthy, 2006). Therefore, research on channeling adolescents' new freedoms into productive actions is essential for preventing high risk behaviors. Additionally, researching actions that reinforce competence and confidence in identity formation for adolescents is needed. One such mechanism is the construct of self-efficacy which can broaden the extent to which an adolescent will pursue interests and goals which fulfill the needs for role resolution (Bandura, 2006). Furthermore, a high level of self-efficacy aids adolescent's decisions to undertake new and challenging tasks as well as persevere in completion of these tasks, which relates to attainment of the ego strength of identity formation which is fidelity (Johnson, Beebe, Mortimer, \& Snyder, 1998).

There are a variety of avenues that can play host to developing values, attitudes, and behaviors of adolescents. Some are after-school programs, youth activities (i.e. out-of-school time, or nonschool hour activities (i.e. Boys and Girls Club, YMCA). Each program provides unique activities and approaches, but the common thread is promoting positive youth development in a safe environment. An adult-sponsored volunteer activity serves not only as one of these avenues but provides additional sources for development, in addition to serving as a protective factor against risk behaviors (Markstrom et al., 2005). Studies support similar 
findings in adolescents who volunteer within adult sponsored programs (Eccles \& Barber, 1999; Markstrom et al., 2005; Wilson, 2000). Adolescents in such programs are more likely to have higher self-esteem (Johnson et al., 1998), higher academic performance (Eccles \& Barber, 1999; Pintrich \& DeGroot, 1990), greater likelihood of college attendance (Eccles \& Barber, 1999), greater sense of community and belonging (Johnson et al., 1998), and more effective identity formation process (Johnson et al., 1998). Accordingly, many extracurricular activities for adolescents are centered on volunteering and provide leadership, responsibility, and problemsolving skills (National Institute on Out-of-School Time, 2008). These are indications that adolescent volunteer opportunities should be able to fill in gaps on adolescent identity and selfefficacy development in the context of an adult sponsored volunteer program.

Interestingly, volunteer rates among adolescents are relatively higher compared to college students and adults (Helms \& Marcelo, 2007). In 2006, 29\% of youth ages 15 to 18 volunteered through an organized volunteer program; in contrast, $18 \%$ of 19 to 24 year olds volunteered (Helms \& Marcelo, 2007). The literature does indicate small yet consistent decreases in volunteer rates over recent years; specifically, decreases of approximately $1 \%$ each year going back to 2002 (Helms \& Marcelo, 2007; United States Census Bureau, 2005). However, adolescents have always had the highest percentage of participation in organized volunteer programs compared to young children and adults (Helms \& Marcelo, 2007; United States Census Bureau, 2005). Additionally, research supports that adolescent volunteers have increased exposure to opportunities that provide self-efficacy and behavioral skills development that assist in identity development and achieving fidelity (Gariglietti, McDermott, Gingerich, \& Hastings, 1997; Wilson, 2000). If this is the case, why are adult sponsored volunteer programs not an integral part of every adolescent's life? 
Running Head: IDENTITY AND SELF-EFFICACY DEVELOPMENT 4

\section{Justification for the Study}

Research on identity formation is a central theme in the adolescent literature. Likewise, self-efficacy is an integral part of adolescent literature, specifically the process of approaching and completing new tasks with confidence (Marcia, 1991). The benefits of adolescents' participation in adult sponsored volunteer programs have been found to advance optimal identity development as well as serving as a protective factor against risk behaviors. Despite these benefits, volunteerism among adolescents continues to decline (Helms \& Marcelo, 2007). Perhaps a closer examination of adult sponsored volunteer programs can lend knowledge to the benefits of youth's participation and increase attendance in this context. This is essential in restructuring existing programs and developing new interventions that can adapt to the evolving wants and needs of adolescents. Furthermore, a lack of existing literature linking self-efficacy, volunteer participation, and identity achievement leaves a gap in adolescent research. These gaps in past literature indicate a need for further examination of the relationship between participation in an adult sponsored volunteer program, self-efficacy, and identity achievement. The pursuit to fill this gap is supported by a limited amount of literature that identifies similar mechanisms within these variables that simultaneously increase identity development and self-efficacy. Therefore, a closer examination of these relationships is a plausible direction for further research.

The following literature is cited to reveal the processes within a specific context in which adolescents can participate in experiences that positively foster identity and self-efficacy development. There are many youth based activities that adolescents participate in; therefore, it is important to specifically identify one context. Generalizing youth activities discredits the unique actions, values, opportunities, skills, and development that each setting can provide (Youniss, McLellan, \& Yates, 1997). In order to differentiate the developmental processes that 
occur within activities, it is vital to review detailed contexts, in this case adult sponsored volunteer activities. For example, two activities both perceived as positive for youth development can vary in methods and results to reach a common goal. Goal achievement was found to be part of the developmental process for adolescents who participated in sports or community groups (e.g. Boy and Girl Scouts of America); however, this gain was attributed to high stress in sports activities and connection with community leaders and organizational goals in community groups (Larson et al., 2006; Scanlan, Babkes, \& Scanlan, 2005). Current gaps in the research do not specify the context, adult sponsored volunteer programs, as an influence on adolescent identity and self-efficacy development. This created a need for these associations to be examined further.

\section{Statement of the Problem}

The need to explore a setting that facilitates positive identity formation in adolescence is vital to engaging youth in volunteer programs so that a healthy identity can be achieved, role confusion resolved, and a strong sense of self-efficacy can be established. Ultimately such programs can enable adolescents to evolve into cognitively, socially, and physically competent adults. The examination of identity formation within the context of adult sponsored volunteer programs may provide knowledge that can lead to lessened negative behaviors and attitudes that jeopardize optimal development among adolescents. In contrast, the 2009 Youth Risk Behavior Surveillance reports that high numbers of adolescents are participating in behaviors that contribute to social problems and high morbidity (YRBS, 2009). Therefore, the need to study youth programs that lead to more positive outcomes were needed. 
Running Head: IDENTITY AND SELF-EFFICACY DEVELOPMENT 6

\section{Statement of the Purpose}

This study sought to fill a gap in the literature that generalizes organized youth activities by specifying the impact of adolescent participation in adult sponsored volunteer programs in relation to identity formation and self-efficacy development. This research will aid in the development of high quality programs that will assist the development of well-adjusted adolescents. There is an increasing need to explore the influences and benefits of adult sponsored programs for adolescents. According to WV Kids Count Data 2008, the Monongalia County teen dropout rate, juvenile delinquency, teen birth rates, and teen injury death rate has dramatically increased every year since 2000. Adult sponsored volunteer activities were chosen because of the current research that supports these contexts as offering positive developmental influences;

however, incorporating identity and self-efficacy as outcomes of participation in these programs needed further exploration. 
Running Head: IDENTITY AND SELF-EFFICACY DEVELOPMENT 7

\section{Chapter 2}

\section{Review of Literature}

This chapter utilizes past research that is significant to the examination of adolescent identity formation, self-efficacy, and participation in a volunteer program. First, this chapter provides a description of organized adult sponsored youth structured activities followed by more specific examination of volunteer programs. Recent findings are presented on adolescents in relation to volunteerism. Then, two theories psychosocial theory (identity vs. role confusion) and social cognitive theory (self-efficacy) were reviewed to establish a theoretical basis for this study. This chapter concludes with empirical evidence from the literature that demonstrates the interrelatedness of identity and self-efficacy, volunteerism and identity, and volunteerism and self-efficacy. The examination of relevant research and results was reviewed to generate hypotheses.

\section{Adult Sponsored Youth Structured Activities}

Positive youth development is the intentional engagement of youth in a wide variety of opportunities and experiences linking them to assets within their community that foster optimal development (Benson et al., 2007; Lerner et al., 2009). A vital contribution of the positive youth development perspective is taking a proactive approach in supporting youths' own abilities and positive contributions to their development (Benson et al., 2007). The goal of adult sponsored youth structured activities is to maximize optimal youth development by providing a safe environment, structure, supportive relationships, sense of belonging, positive social norms, support for efficacy, and skill building (Benson, Scales, Hamiliton, \& Sesma, 2007; National Research Council, 2002). Adult sponsored volunteer programs for adolescents possess elements that are designed to aid developmental processes (National Research Council, 2002). Adults that 
design and sponsor these programs aim to create contexts that offer the conditions that are favorable for positive youth development (Larson, et al., 2006). These conditions can be offered in a variety of structured activities. Extracurricular activities are school based and occur after regular school hours encompassing a broad range of activities such as athletics, debate team, and student government (Larson et al., 2006; Markstrom et al., 2005). Community based activities (e.g., Boys and Girls Scouts of America, 4H, Scouting) seek to network youth with peers, community adults, and opportunities that can socialize and build skills for future opportunities (Larson et al., 2006). Faith-based groups are organizations that connect youth with their belief system, peers, and community through activities such as youth groups, choir, and Bible study (Larson et al., 2006; Markstrom et al., 2005). All of these activities may engage adolescents in volunteer activities. There are also organized volunteer programs solely focused on performing activities that benefit the community and instill social responsibility within the youth. Additionally, volunteer programs require cooperation and flexibility in meeting the needs of the volunteers, the organization, and the community being served (Cemalcilar, 2008; National Research Council, 2002). It is useful to keep in mind that just because something is designed for youth, it may or may not result in youth development. That is why it was important to examine the mechanisms that foster optimal development as conducted in this study. The next section continues the topic of adult-sponsored structured activities according to the magnitude and impact of adolescent volunteerism.

\section{Adolescent Volunteerism}

Volunteerism is an intentional and optional prosocial activity that benefits individuals, beliefs, and communities (Cemalcilar, 2009). Volunteerism lends many positive benefits to society; in addition, the volunteer providing the service gains psychological and social benefits 
(Wilson, 2000). Many studies in the past have focused on adult volunteerism; however, an increasing amount of literature is emerging on youth volunteers (Johnson et al., 1998). Furthermore, these studies have targeted developmental outcomes such as personal growth, role resolution, and commitment to ideals, prosocial attitudes, empathy, and evolving self-perceptions within the adolescent. Volunteer experience contributes to identity (Cemalcilar, 2009; Larson et al., 2006; Reimer et al., 2009). A broader picture of adolescent volunteer trends was needed to capture the connections between youth and volunteering.

The Youth Volunteering Survey was created by the Corporation for National and Community Service in collaboration with the U.S. Census Bureau to begin to piece together a better understanding of the growing involvement of adolescents and teens in volunteer activities. Over a three month period in 2005 3,178 American youth ages 12-18 answered questions about their volunteer behaviors. According to this survey, 15.5 million teens engaged in volunteer activities during 2004, equaling 1.3 billion hours of service. Sixty-four percent volunteered with an adult sponsored volunteer program. Thirty-nine percent of these teens volunteered regularly (Grimm, Spring, \& Dietz, 2010). The most recent volunteer trends account for an increase of 1.6 million additional volunteers between 2008 and 2009 (Grimm et al., 2010), a national trend that suggests a desire for youth to participate in programs that provide volunteer opportunities.

Volunteer programs are a significant part of the extended learning process for adolescents. This age group can spend 20 to 25 hours per week unsupervised and this number dramatically increases during the summer months (National Institute on Out-of-School Time, 2008). Furthermore, in reference to the school year, $14.3 \%$ of adolescents are not involved in any type of adult sponsored organized program (National Institute on Out-of-School Time, 2008). The statistics indicate large numbers of adolescents both participating and not participating in 
adult sponsored programs. The level of participation and growing amount of youth volunteerism research makes it important to continue examining the impact adult sponsored volunteer programs have on adolescents' development. The following literature expands on research based outcomes of adolescents who participate in adult sponsored volunteer programs.

Several studies support the relationship between adult sponsored volunteer programs and adolescents' positive short term and long term development (Eccles \& Barber, 1999; Eccles et al., 2002). For example, studies found that participation in volunteer youth programs increased the likelihood of positives outcomes as adults such as higher education, occupational achievement, and mental well-being (Eccles \& Barber, 1999). Adolescents who choose to participate in programs that focus on the aspect of organized volunteerism can create a positive context outside of the home that provides opportunities for identity and self-efficacy development (Eccles et al., 2002). Volunteerism is a resource for role relationships and a context in which social norms can be acquired and tested (Markstrom et al., 2005). Adult sponsored volunteer programs initiate adolescents into a stage in which understanding and commitment to particular goals, values, and beliefs shape their identity development (Markstrom et al., 2005; Youniss et al., 2005). Additionally, the literature has identified several outcomes that are related to adolescents' participation in adult sponsored volunteer programs. As Johnson et al. (1998) pointed out, volunteerism during adolescence fosters high self-esteem. Also, academic success, community involvement, and disassociation with negative behaviors is linked to participation (Eccles \& Barber, 1999; Youniss et al., 1999). Adult sponsored volunteer programs that engage youth in constructive and challenging activities foster positive self- perceptions, competency, and encourage their abilities and skills, creating a framework for positive identity development and positive self-efficacy (Perkins, Borden, \& Villarruel, 2001). The preceding discussion presents 
central concepts of this study, adult sponsored youth structured activities and adolescent volunteerism; additionally, the following discussion will examine these concepts through Erikson's (1968) psychosocial theory and Bandura's (1986) social cognitive theory construct self-efficacy.

\section{Theoretical Framework: Psychosocial Theory}

Erikson's psychosocial theory presents an explanation for the development of individuals across the life-span and within the context of family, society, and culture (Erikson, 1968). One life stage that is explored is adolescence (ages 12-19). Youth at this age somewhat shed their parents' identities and begin to culminate the experiences, values, behaviors, ethics and attitudes that will shape who they are as individuals (Erikson, 1950). A newly shaped self-concept emerges influenced by a broad range of socialization agents, such as peers, media, community, and organized activities. Therefore, the psychosocial theory was used to support this studies hypothesis that participation in an adult sponsored volunteer program results in high levels of the ego strength of fidelity posttest compared to pretest.

According to Erikson (1950), experiences, values, behaviors, ethics and attitudes serve as a framework that guides an individual's daily activities; this is referred to as identity. Erikson's developmental theory presents adolescence as a time of unification of the identity. As said by Erikson (1950), this psychosocial stage, identity vs. role confusion, occurs during adolescence and is the catalyst for the transition from childhood to adulthood. The emerging identity takes form when an adolescent bridges past experiences with future intentions and cultivates their own ideologies. Erikson explains eight stages that a developing person will pass through across the life span. It is assumed that upon mastering the developmental tasks, they will be prepared for ascendance into the following stage (Markstrom et al., 2005). Additionally, attainment of the ego 
virtue contributes to a rich and dynamic life course (Markstrom et al., 2005). Erikson viewed the ego virtues or what is also called, ego strengths as naturally internal strengths that are present throughout the life span but only fully acquired in a psychosocially well rounded person (Markstrom \& Kalmanir, 1998). Erikson (1964) postulated that the eight ego strengths transpire in accordance with the achievement of the associated psychosocial life stage crisis. However, an individual ego strength can only emerge and thrive once the psychosocial crisis has been resolved; In addition, individuals will experience interactions within their surrounding environments that will shape the process of ego strength obtainment and ascendance.

Individuals progress through the stages of life, infancy to late adulthood and similarly through the stages of psychosocial development as articulated by Erikson. However, if the challenges of a particular stage are not mastered problems may be imminent. The stages provide practices that modify the development of the individual and ideally shift their cognitive and behavioral abilities to a higher degree. Erikson (1964) describes each psychosocial stage as a crisis due to the exploratory and often confused state that individuals experience throughout the transition. However, a fundamental component of psychosocial stages is the ego strength, which is only obtained in psychosocially healthy individuals (Markstrom et al., 1998). In particular, individuals ascend through the psychosocial stages as follows and obtain the ego strength accordingly; hope from basic trust vs. mistrust (age 0-1), will from autonomy vs. shame or doubt (age 2-3), purpose from initiative vs. guilt (age 4-6), competence from industry vs. inferiority (age 7-11), fidelity from identity vs. identity confusion (age 12-19), love from intimacy vs. isolation (age 20-34), care from generativity vs. stagnation (age 35-65), and wisdom from integrity vs. despair (age 65 and up) (Erikson, 1964). Erikson's perspective on development is useful to our understanding of adolescent identity development because he acknowledged the 
interaction between social experiences and adolescents' identity development. Furthermore, for purposes of this research Erikson contributes the importance of personal ideologies for adolescents to ascend through the stage and achieve fidelity.

\section{Identity and the Ego Strength of Fidelity}

As explained, the ego strengths correspond with the psychosocial stages. For example, fidelity is the ego strength gained with resolution of the identity crisis during adolescence. Fidelity is the dedication to one's self-beliefs and sustaining these beliefs despite opposition (Erikson \& Erikson, 1982). The strength is derived from the interactions of the individual's behaviors and attitudes in accordance with familial, social, and cultural expectations (Erikson, 1985; Markstrom \& Kalmanir, 2001). Erikson postulated that social environments are essential for adolescent identity development, specifically fidelity (Erikson, 1965). Several studies indicate that the social environment of adult organized programs can offer this framework (Eccles \& Barber, 1999; Fletcher \& Shaw, 2000; Markstrom \& Kalmani, 2001). Marsh and Kleitman, (2003) found that adolescents who participated in adult sponsored volunteer programs were more likely to be dedicated to the mission of the organization and commitment to their role and opportunities within the organization (Eccles \& Barber, 1999). This fulfills several variables for fidelity achievement through: social development, self expression, role attainment, faithfulness to a cause, and skill development (Eccles \& Barber, 1999; Fletcher \& Shaw, 2000). The resolution of the psychosocial stage and achievement of the ego strength of fidelity creates a foundation, for further growth (Erikson, 1965).

In contrast, when this strength is not utilized in a context that aids positive development, responsibilities and new experiences are not a priority which hinders identity development. Marcia (1966) would offer the explanation of identity status for these scenarios. Depending on 
the degree of exploration and commitment four statuses characterize an adolescents' measurement of identity attainment. First and most optimal, achievement is reached when exploration has resulted in a commitment to particular values, beliefs, choices, and attitudes. Adolescents in moratorium are in the process of exploration but have not yet committed. Next, foreclosure occurs with an often impulsive commitment without exploration. Finally, diffusion is the status of adolescents at high risk for risk behaviors, no exploratory actions have been taken along with no commitment to any plans or tasks. Erikson postulates that achievement will yield fidelity attainment (Erikson, 1965). The exploration processes of adolescence engage youth in activities that provide the opportunity for commitment to goals. These processes strengthen their self-perception and belief in attaining goals.

\section{Social Cognitive Theory: Self-Efficacy}

A key construct of social cognitive theory is self-efficacy (Bandura, 1986). Self-efficacy is one's beliefs about their capabilities to produce desired outcomes in their lives (Bandura, 1994). Self-efficacy can be broken down into three subcomponents to determine an individual's capability of completing a particular task: magnitude, strength, and generality (Bandura, 1986). First, self-efficacy magnitude is the degree of difficulty a person believes they will be able to accomplish (Bandura, 1986). Secondly, self-efficacy strength is the degree of confidence a person has in performing a task (Bandura, 1986.) Lastly, self-efficacy generality is how a person's past successes or failures modifies their self-efficacy for future behaviors (Bandura, 1986). The above subcomponents provide a more multi-dimensional assessment of self-efficacy and establish it as an appropriate construct for inquiring more on adolescents' motivations for participating in adult sponsored volunteer programs and identity development. For instance, studies have found cognitive, emotional, attitudinal, personality, and social development to be 
dependent on self-efficacy expectancies (Dauberman, 2008; Holden, Moncher, Schinke \& Barker, 1990).

The belief in one's capabilities is the driving force for one's motivations, behaviors, feelings, and cognitive processes (Bandura, 1994). As stated in social cognitive theory, people gradually develop perceptions of their own abilities and behaviors that will determine how much effort they put in to setting and achieving goals (Bandura, 1977). According to social cognitive theory, people play a proactive role in their own development and are in control of making things happen for themselves (Pajares, 2002). However, Bandura (1994) stated that to build selfefficacy organized structures must be in place to guide successful experiences if any positive developmental change is to take place. Hedin and Conrad (1980) found adolescents who participated in organized volunteer programs had higher posttest results than the control group in the areas of self-efficacy and self-efficacy in social contexts. Furthermore, adolescents that participate in collective efforts for societal change enhance commitment and their capability to reach their goals (Bandura, 2006).

This theory is important in providing an explanation for where the inner drive comes from to compel adolescents to commit to and reach their goals (Bandura, 1994). In addition, selfefficacy guides adolescents through this transitional stage of development by expanding the exposure to new opportunities, skills, and ideals that adolescents can commit to for future endeavors (Bandura, 2006). Adolescents' self-efficacy can impact the roles they choose to take which directly shapes their role resolution and identity development. The organization and structure that an adult sponsored volunteer program offers provides adolescents the support and guidance needed to succeed in experiences that foster self-efficacy and fidelity. 
The two theoretical perspectives for this study are psychosocial theory and social cognitive theory. Psychosocial theory is pertinent to this study because it provides an explanation for the identity development of adolescents in particular, achievement of the ego strength of fidelity. This framework offers an explanation for the processes of identity development while the social cognitive theory explains the need for one's beliefs in their capability to reach goals and attain self-efficacy. It is speculated that self-efficacy impacts the likelihood of participation in adult sponsored activities which, in turn, can further enhance self-efficacy development. Both self-efficacy and participation in activities are suggested to influence identity formation. Therefore, the bidirectional relationship between self-efficacy and participation in adult sponsored activities influences identity formation. Achievement of the ego strength of fidelity can connect an individual to more experiences and attained goals which provide an opportunity to continue and strengthen self-efficacy. There are some activities that facilitate identity formation and self-efficacy. The following research examined these connections and links participation in volunteer activities as a predictor of these outcomes.

\section{Identity and Self-Efficacy}

Adolescence is a critical time not only for identity development but for self-efficacy (Gariglietti et al., 1997). Research trends at this particular stage in development present evidence for declines in adolescents' assertiveness, confidence, and self-efficacy and instead adolescents present poor self-images, decreased confidence, and reluctance to participate in new activities (Eccles et al., 1993; Gariglietti et al., 1997). Identity confusion in unison with decreased selfefficacy can compound an already tumultuous stage for some adolescents (Bandura, 2006). Additionally, negative changes even subtle ones can discourage an adolescent from engaging in personal and social explorations that can hinder the development of a healthy identity. In 
contrast, adolescents who believe in their skills and capabilities are more likely to attempt, persist, and succeed in new behaviors which progresses the transition through stages of identity development and enhances self-efficacy (Larson et al., 2006). Self-efficacy consequently motivates the attempt of new behaviors and experiences, which ultimately continues the identity development process. There are few studies that look at the relation between identity and selfefficacy. However, there is some evidence that supports this relationship presented below.

Markstrom and Marshall (2005) examined identity achievement and the connection to the ego strength of fidelity and locus of control using the psychosocial inventory of ego strengths (PIES) measurement. Locus of control is not self-efficacy but is similar in that individuals perceive their capabilities as the reason for particular outcomes. For example, individuals with high locus of control believe that goals and outcomes are met because of their own behaviors and efforts. For this study, data were collected from 502 adolescents in the $10^{\text {th }}$ and $11^{\text {th }}$ grades from across West Virginia. A series of measurements were used to assess ego strength as being representative of identity achievement. The following measurements are most relevant to the findings for identity and self-efficacy. The PIES consists of 64 questions that measure the eight ego strengths. The Extended Objective Measure of Ego Identity Status (EOMEIS) was used to determine the level of exploration and commitment to domains of identity according to Marcia's identity statuses of diffusion, foreclosure, moratorium, and achievement. The NowickiStrickland locus of control scale is a 21 -item true or false measurement used to determine individual's belief in their efforts to achieve goals. The culmination of results indicated that overall PIES scores were significantly connected to internal locus of control. Specifically, the subscale on fidelity was significantly correlated to internal locus of control. Fidelity is the ego strength indicative of identity achievement. 
Similarly, Phillips and Pittman (2007) proposed that identity style would be predictive of psychological well-being, determined by self-esteem, hopelessness, delinquent attitudes, educational expectations, and efficacy. A total of 262 adolescents from summer camps, youth centers, and a high school were first administered the Identity Style Inventory-Revised for a Sixth-Grade Reading Level (ISI-6G). Identity style (informational, normative, and diffuse/avoidant) was assessed by the 40 item measure. Similar to Marcia's identity statuses Berzonsky's (1990) identity styles associate informational style to exploration and commitment, normative behavior to less of a commitment, and diffuse/ avoidant to lack of concern for future consequences. Next, to determine psychological well-being, participants completed the Rosenberg's Self-Esteem Scale (RSE), Hopelessness Scale for Children (HSE), and the Delinquent Attitude Scale (DAS). Phillips and Pittman's (2007) findings suggest that identity style is related to self-esteem, hopelessness, delinquent attitudes, educational expectations, and efficacy. The more developed identity styles, informational and normative, were significantly related to attitudes of efficacy and self-esteem than the less developed style, diffuse/avoidant. Additionally, similar correlations were found between the identity styles and well-being and hope for future goals. Diffuse/avoidant style participants were found to be much less optimistic, have lower self-esteem, and efficacy. This research is consistent with other findings that the development of identity is related to higher levels of self-efficacy.

Research is limited, but it is suggestive that self-efficacy is related to identity development. Identity formation is a dynamic process and adolescents varying levels of identity exploration result in differing levels of intrinsic motivation and goal orientation, such as selfefficacy. Variation in the degree of identity and self-efficacy development can be further explored 
by examining the contexts within which these processes occur. An adult sponsored volunteer activity is one context that links to identity and self-efficacy as the following research indicates. Volunteerism and Identity

Adult sponsored volunteer programs serve as a unique avenue for adolescents to serve those in need. For many youth, these experiences are their first encounter with on-going responsibility and new social experiences with which they are unfamiliar, misguided, or have skewed opinions on. Therefore, volunteerism offers a chance for self-reflection and interpretation of adolescents' actions in the true societal context of the interaction. Youniss et al. (1999a) propose that volunteer programs are particularly important contexts for fostering adolescent identity development by offering socially acceptable roles, procedures, norms, and values along with a committed responsibility to service that aid adolescents in their identity choices. This coincides with the main attribute of fidelity which is commitment. Furthermore, adolescents must have a social foundation to build their ideals, values, and beliefs; this is often obtained by experiencing meaningful activities that reflect adults' social norms (Youniss et al., 1999b). According to Youniss et al. (1999b) volunteerism provides an orientation to societal norms and expectations, which is imperative to identity development in adolescents according to their belief in themselves and their contributions to society. The following research supports this connection between volunteerism and identity.

Reimer et al. (2009) conducted a study examining adolescent identity development and moral maturation through participation in organized volunteerism among 1,550 low-income at risk public high school students grades 9-12. Volunteerism was assessed beginning with a panel of community leaders identifying volunteer opportunities specific to the region so options would be relevant to participants. Eight areas of volunteerism were identified such as church, 
community service, and environmental causes. Twenty-two questions were derived from the eight areas of volunteerism to assess participants' frequency and motivations for volunteerism. Identity development was measured by the Walker and Pitts (1998) self-understanding questionnaire administered through an interview to assess goal setting and self-evaluation. Reimer et al. (2009) found that volunteer commitment was associated with setting personal goals for themselves and moral attainment. A participant's commitment to organized volunteering was found to be indicative of moral maturity and impact identity development which was represented as self-understanding.

Larson et al. (2006) studied the differences in developmental experiences of 2,280 eleventh graders from 19 diverse high schools. Differences in developmental experiences were compared between adult sponsored programs: sports, arts, academic clubs, community groups, volunteerism, and faith based activities. Participants completed The Youth Activity Inventory which assessed the activities participants had took part in within the last three months. The Youth Experiences Survey (YES) Version 2.0 consists of 70 items assessing personal, interpersonal, and negative developmental experiences in organized activities. The personal subscales focus on identity exploration, initiation, and emotional regulation development during participation in the activities identified in The Youth Activity Inventory. Twenty-seven percent of participants reported participation in an organized volunteer activity. Utilizing the Youth Activity Inventory and YES participants reported higher rates of identity exploration, initiation, teamwork, adult mentors, and positive relationships. The results indicate volunteerism as enhancing aspects of interpersonal and personal development; however, interpersonal development, in particular social skills and prosocial norms, increased more than personal development. This suggests that the development of positive social networks linked to volunteerism can further identity exploration. 
Eccles et al. (2003) examined and reviewed literature from the Michigan Study of Adolescent Life Transitions (MSALT) in which a longitudinal study was conducted with 1,800 participants from sixth grade to age 26 to determine participation in an extracurricular activity, including volunteerism, in association with developmental outcomes. Eccles et al. (2003) studied the initial $1,25910^{\text {th }}$ grade participants' extracurricular and volunteer activity involvement as an indicator of educational and risk behavior outcomes. Consistent with previous research, participation in adult sponsored activities enhances the positive development of adolescents as opposed to no involvement at all. Additionally, longitudinal regression analyses were conducted with data from the $10^{\text {th }}$ grade and $12^{\text {th }}$ grade and found volunteer and community service participation influenced academic achievement, motivation, and engagement in less risky behaviors than their non-participating peers. Results indicate that participation in organized volunteer activities serve as a context for identity formation by providing exploration for values, attitudes, and behaviors to which adolescents can commit.

In a similar study, Youniss et al. (1999a) built upon previous research and studied community service participation as a positive influence on identity formation. Data from 13,000 participants were used from the Monitoring the Future Survey, a longitudinal study of high school seniors that assesses behaviors and attitudes of adolescents and teenagers. Participants reported frequency of participation in a variety of daily activities; sports, hanging out, performing arts, community service, religious groups, political groups, and marijuana use, which were identified as predictors of normative, unconventional, and deviant orientations. Normative behaviors were represented by conventional political involvement (e.g. volunteerism, voting, religious attendance), unconventional behaviors were indicated by boycotting, and deviant behaviors were indicated by marijuana use. Results signify the frequency of community service 
participation as a significant predictor of varying degrees of normative, unconventional, and deviant behaviors and attitudes. The normative behaviors, which encompassed organized volunteerism, were found to introduce activities, values, and attitudes that were often adopted and integrated into one's identity formation processes. This finding suggests that community service participation influences, guides, and provides protective factors for the developmental orientations of youth.

Most relevant to the present study Markstrom et al. (2005) examined ego strength association with participation in extracurricular, volunteerism, and religious adult-sponsored structured activities among 517 West Virginia high school students. Participants' responses were analyzed according to current involvement in adult-sponsored structured activities and Psychosocial Inventory of Ego Strengths (PIES), a 64 item valid and reliable assessment for measuring the eight ego strengths. Responses were analyzed using the multivariate analysis of covariance (MANCOVA) to assess structured activity involvement and ego strength. Findings identify volunteerism as highly associated with several ego strengths including fidelity which is indicative of identity formation. Interestingly Markstrom's et al. (2005) longitudinal analysis found initial ego strength to influence involvement in activity participation. These findings suggest that attainment of prior ego strengths influences participation in adult sponsored activities. In particular, volunteerism can encourage and provide opportunities for positive developmental processes. Adult sponsored activities that encompass volunteerism provide an orientation to societal norms and expectations, which is imperative to identity development in adolescents and their belief in themselves and their contributions to society (Youniss et al., 1999b). 
The developmental outcomes of identity development can be derived from the challenging tasks, new experiences, and social norms offered by some adult sponsored volunteer programs. The accomplishments resulting from volunteerism in an organized adult program can assist in strengthening one's self-efficacy. Furthermore, the degree of positive self-belief can encourage new experiences that further identity exploration. The following research on volunteerism and self-efficacy demonstrates another connection, in addition to identity and selfefficacy as well as volunteerism and identity. There is limited evidence to show that self-efficacy and participation in adult sponsored volunteer programs are related.

\section{Volunteerism and Self-Efficacy}

Adolescents who believe in their skills and capabilities are more likely to attempt, persist, and succeed in new behaviors which progresses the transition through stages of identity development and enhances self-efficacy (Larson et al., 2006). Self-efficacy consequently motivates the attempt of new behaviors and experiences which ultimately continues the identity development process (Johnson et al., 1998; Larson et., 2006). As discussed earlier, adult sponsored volunteer activities serve as an optimal context for motivation, skills, and knowledge to emerge and transpire into positive self-perceptions. Self-efficacy is one of many benefits gained through participation in volunteer activities that contributes to positive development, particularly in adolescents (Ryder, 2005). Adult sponsored volunteer activities serve as a source for enhancing self-efficacy as presented in the proceeding review.

Similarly Johnson et al. (1998) posited that previous characteristics, volunteerism, and psychological outcomes are associated. Data from the Youth Development Study, a longitudinal study of $1,0009^{\text {th }}$ to $12^{\text {th }}$ graders and their developmental adjustment in relation to educational/ vocational experience, was utilized to identify prerequisites and altruistic outcomes of organized 
youth volunteering. An important aspect of this study can be the generalizability of the representative sample of adolescents. Yearly questionnaires were administered over a four year span to acquire the results. Participants with preliminary reporting of high self-esteem and intrinsic motivation were more likely to volunteer, suggesting that higher levels of identity development increase volunteering which results in positive psychological outcomes including aspects of self-efficacy. It was found that volunteerism in adolescence is associated with setting personal goals, further community service, motivation, and academic self-efficacy. Additionally, higher self-esteem, academic success, and goal setting progressively increased longitudinally from grade $10^{\text {th }}$ to $12^{\text {th }}$ grade. Volunteerism was also found to be significant in participants' anticipation of successful careers and work ethic. Johnson et al. (1998) found developmental advancements in aspects of self-efficacy to be influenced by volunteerism.

Ryder (2005) conducted a study examining the association between volunteerism and psychological well being, evaluated as amount of volunteerism, career self-efficacy, hope in social relationships, hope in academic performance, hope in work, dispositional hope, optimism, and gratitude, among 383 undergraduate college students. The review of literature included a lengthy discussion of adolescent volunteerism and the psychological benefits derived at this stage to build a better understanding of continual developmental outcomes into the early adult years. Participants were administered the Career Decision Making Self-Efficacy Scale-Short Form to assess determination, self-perceptions, and ability to pursue career goals. The Adult Dispositional Hope Scale was administered to determine the goal-orientation and motivation of participants through 12 self-report statements. Additionally, several scales evaluating confidence and self-esteem were utilized. The results were inconsistent with other research findings, indicating no significant correlation between volunteerism and psychological well-being. Ryder 
(2005) did not dismiss the results but encouraged future research for additional variables that may correlate volunteerism and aspects of psychological well-being.

Wood, Larson and Brown (2009) studied the development of adolescents' responsibility in the context of organized youth programs that offered volunteer opportunities. This research is relevant to this study because Wood et al. (2009) examined responsibility in terms of setting personal expectations and forming behavioral patterns for the future, similar to self-efficacy. One hundred and eight students that participated in youth programs from 11 high schools were interviewed, every two weeks ranging from two to nine months. Students were interviewed about their responsibility development and the progression of this development within the programs. Twenty-four participants reported increases in responsibility. Despite the moderate findings Wood et al. (2009) noted that interviews consisted of open ended questions and adolescents may attribute responsibility to other qualities. However, responses from these participants indicated a strong link between responsibility, motivation, and participation in organized youth programs. Responses represented commitment to goals, taking on new tasks and roles, and anticipating positive achievement. The findings indicate that participation in organized youth volunteer programs is a context that offers access to roles and experiences that are internalized as responsibility and motivation for current and future endeavors.

There are few studies but there was evidence within these studies that demonstrated the potential of adult sponsored volunteer activities to be a context in which adolescents gain the ability to be autonomous and achieve intrinsic motivation to reach new goals and commitments. Self-efficacy has been demonstrated to be an antecedent to participation in adult sponsored volunteer programs. Additionally, participation within this context produces intrinsic motivation through the processes of the program which manifests as increased self-efficacy. 


\section{Summary}

Psychosocial theory was used in this study to explain why adolescents' participation in adult sponsored activities can bolster positive identity formation and feelings of self-efficacy. The social cognitive theory was used to explain the importance of gaining the belief in one's capabilities to experience and succeed in new contexts thus committing to ideals and obtaining role resolution. These theories are used within this area of research and are established theoretical models for understanding adolescents' identity and self-efficacy development. Adolescence is often reported to be a difficult physical, emotional, and behavioral transitional stage; however, adult sponsored volunteer programs have been recognized as a protective factor for risk behaviors and methods for enhancing positive development.

This chapter provided literature to support the connections between adult sponsored volunteer programs, identity development, and self-efficacy. The overall findings from prior research suggest that adult sponsored volunteer activities are a context appropriate for the development of identity and self-efficacy. Despite these connections and theoretically relevant constructs, a current lack of evidence exists in determining whether and to what degree participation in an adult sponsored volunteer program influences identity and self-efficacy among adolescents. Therefore the purpose of this study was to determine whether participation in an adult sponsored volunteer program enhances levels of self-efficacy and identity.

\section{Statement of Hypotheses}

It was hypothesized that: (1) adolescents who participate in an adult sponsored volunteer program will have higher levels of the informational style of identity posttest compared to pretest; (2) adolescents who participate in an adult sponsored volunteer program will have lower levels of normative and diffuse identity styles posttest compared to pretest; (3) adolescents who 
participate in an adult sponsored volunteer program will have higher levels of commitment posttest compared to pretest; (4) adolescents who participate in an adult sponsored volunteer program will have higher levels of the ego strength of fidelity posttest compared to pretest ; (5) adolescents who participate in an adult sponsored volunteer program will have higher levels of self-efficacy posttest compared to pretest 
Running Head: IDENTITY AND SELF-EFFICACY DEVELOPMENT 28

\section{Chapter 3}

\section{METHODS}

This study examined identity and self-efficacy development among 28 adolescents enrolled in The Shack Neighborhood House's junior volunteer program. Since 1928, the vision of The Shack Neighborhood House has been to be: "A Community Center Serving Family Needs." This is done through the mission to provide an organization that will enhance growth and development through spiritual, social, recreational, educational, economic and health programming to all people of Scott's Run, WV and surrounding areas. One program that serves to meet these goals is the junior volunteer program. The purpose of this program is to provide middle and high school students an avenue to participate in community service, skill building, recreational, and social activities. Recent activities include building a handicap ramp for an elderly gentleman, rail trail maintenance/beautification, raking leaves, serving the children's summer day camp, home repairs, among numerous other projects. During the summer of 2011, junior volunteers completed a total of 3, 676 volunteer hours.

The study was an experimental research design involving one experimental group that was pretested and posttested. Initial data were collected on the first Friday of the program or as soon as guardian consent and participant assent was gained. Three participants enrolled after the initial start of the program and were administered the pretest upon starting the program. The three participants all enrolled within the first three weeks of the program. Next, participants took part in program activities for the span of the 11-week program, in which they spent an average of 7.5 hours a day Monday through Friday. Posttest data was collected on the final day of the program. Three participants were not present at this time. The circumstances for their absence 
made data collection necessary via phone contact and mailing of the posttest. Posttests were completed and returned in the provided self-addressed stamped envelope.

\section{Participants}

There were 28 junior volunteers ages $12-18$ with a mean age of 14 that participated in the study. The participants included 16 males and 12 females ranging from grades $7^{\text {th }}$ to $12^{\text {th }}$ with $32.1 \%$ in the $7^{\text {th }}$ grade, $14.3 \%$ in the $8^{\text {th }}, 32.1 \%$ in the $9^{\text {th }}, 14.3 \%$ in the $10^{\text {th }}$ grade, and $3.6 \%$ in both the $11^{\text {th }}$ and $12^{\text {th }}$ grades. The sample was composed of $96 \%$ Caucasian and $4 \%$ African American adolescents. Thirty-nine percent of the participants indicated receiving free or reduced lunch which the state of West Virginia uses to indicate economically at risk youth. Participants' volunteer service ranged from 27 to 240 hours over 11 weeks. These participants completed both pretest and posttest measures on which the analyses were conducted to test the study's hypotheses.

These adolescents were primarily from the Scotts Run area of a greater metro-suburban area in Monongalia County, West Virginia, population of 96,189 (U.S. Census, 2010). This community is on the edge of the city and though it utilizes resources from the city it retains traditional Appalachian characteristics.

\section{Procedure}

An initial letter explaining the purpose of the study and requesting guardians' consents was handed out to all of the guardians the first day of the each participant's start (see Appendix A). Consent was received from 31 guardians by Friday of the first week.

Participants met as a group early in the morning on the first day of the program and an overview of the study was explained by the researcher. Following this introduction questions or concerns were answered. Next, the researcher distributed the assent forms (see Appendix B). 
Once the researcher confirmed that consent and assent forms had been signed and received, the data collection process proceeded. The consent forms were acquired during the first week of the program and were followed by data collection on Friday of the first week. The measures were administered on-site in a classroom where the group regularly meets. A demographic survey and all of the study's measures were administered on Friday of the first week of the program during the afternoon meeting, which is held daily after lunch. The researcher administered the measures. Participants were allowed as much time as necessary to complete the surveys and all participants completed the measures within 30 minutes or less. Pretest data was collected by administering the four measures: (a) a demographic survey; (b) an identity style measure to evaluate style of identity; (c) an ego strength measure to assess psychosocial maturity; (d) a self-efficacy measure to collect data about perceived self-beliefs for future goals. The participants each received a packet with an assigned number in the top right hand corner of the front page. This number was assigned in the database to each participant. Following completion of surveys, participants took part in the 11-week summer program. Participants were able to exit the program and the study at any time without penalty or consequences. Thirty-one participants completed pretest measures but data from only 28 participants were useable. One participant did not complete the program and two did not reach a sufficient number of volunteer hours to be included (less than 25 hours). The measures were readministered posttest the last day of the program following the same protocol as the first day. Three participants were not present on this day and were contacted and requested to return to the Shack for completion of the measures. Due to the fact that they had moved out of the area the researcher mailed the posttest survey along with a self-addressed stamp and all posttests were completed and returned. 
Running Head: IDENTITY AND SELF-EFFICACY DEVELOPMENT 31

\section{Instrumentation}

Demographic. Participants were given a demographic survey to complete on grade, age, gender, and ethnicity. These items are shown in Appendix C.

The Identity Style Inventory-Grade 6 (ISI-6G). Participants' identity style was examined using a revised version of Berzonsky's Identity Style Inventory (1992) (see Appendix D). White (1998) modified the ISI-6G to accommodate diverse reading levels while still being able to accurately assess three varying styles of identity orientations: (a) informational style which represents exploration and commitment to goals; (b) normative style which encompasses commitment to goals but without exploration; and (c) diffuse and normative avoidant styles which reflect impulsiveness and a lack of long-term goals. Finally, commitment which is not an identity style but an associated variable of the orientations was used to assess the degree of dedication one associates with personal values, behaviors, and beliefs (see Appendix D). There are 11 informational, 9 normative, 10 diffuse/avoidant style questions, and 9 commitment questions. One commitment item was inadvertently excluded. Number 14, "I'm really interested in an area of study that I want to study in college, trade school, or higher education," was not included. Despite this item not being included the subscale still had acceptable reliability as indicated in Table 1. Therefore, respondents completed 39 items with responses indicated on a 5point scale ranging from 1-strongly disagree to 5-strongly agree. Example of items include: "I don't pretend to be something that I'm not," from the information subscale, "When I make a commitment to something, I stick with it," from the normative subscale, "I find that my opinions are frequently influenced by others," from the diffuse subscale and "I am interested in an academic area that is right for me," from the commitment subscale. The ISI-6G has been found to be a valid and reliable measure for measuring adolescences' and adults' identity styles. Phillips 
and Pittman (2007) utilized the ISI-6G, as indicated earlier in the literature review, because of its reliability in measuring adolescents' identity style. Berzonsky (1992) reported reliability for each identity style: informational $\alpha=.70$, normative $\alpha=.70$, and diffuse/avoidant $\alpha=76$.

Psychosocial Inventory of Ego Strength (PIES). Participants completed the PIES measurement (see Appendix E). This measure was created by Markstrom et al. (1997) to measure Erikson's eight ego strengths in terms of psychosocial development and adjustment. The 64-item measure is divided into eight subscales composed of eight questions each representing the ego strengths (hope, will, purpose, competence, fidelity, love, care, and wisdom). The subscale of fidelity is of particular importance to the current study and is the only subscale that was used. The fidelity items were developed to assess identity achievement and the emergence of fidelity with items such as "When I make a commitment to something, I stick with it." The items are responded to on a 5-point scale ranging from 1-does not describe me well to 5-describes me very well. Markstrom et al. (1997) conducted research to determine internal consistency of PIES. Additionally, it has been found to be a reliable and valid measure for psychosocial development among high school students (Markstrom \& Marshall, 2007). The 8-item subscale of PIES for the ego strength of fidelity was $\alpha=.75$ and $\alpha=.93$ for the overall measure (Markstrom et al., 1997).

The General Self-Efficacy Scale (GSE). Participants completed the GSE developed by Schwarzer and Jerusalem (1995) to assess perceived self-efficacy with completing daily tasks as well as long-term goals (see Appendix F). Additionally, this measure addresses the self-belief that one is competent to face challenging tasks. The 10-item scale uses a response format of 1being not true at all, 2-hardly true, 3-moderately true, and 4-exactly true. Example items include: "It is easy for me to stick to my aims and accomplish my goals," and "I am confident that I could deal efficiently with unexpected events." Scores were configured by adding up each item 
response. Scores ranged from 10-40 with higher scores indicating higher levels of self-efficacy. Schwarzer and Jerualem (1995) cited numerous studies and reported a range of alphas $\alpha=.76$ to $\alpha=.90$, averaging $\alpha=.80$.

\section{Analytic Strategy}

Each measure and subscale was analyzed showing Cronbach's alpha to exhibit internal consistency of the measures. Pearson correlations were run on all measures to determine the statistical relationships between each measure. Finally, to test the hypotheses, paired $t$-test scores were used to compare differences in pretest and posttest scores on identity style subscales, commitment subscale, ego strength of fidelity, and self-efficacy. SPSS Statistics 19 was used to analyze all data. 
Running Head: IDENTITY AND SELF-EFFICACY DEVELOPMENT 34

\section{CHAPTER 4}

\section{Overview}

\section{RESULTS}

The following section will present the quantitative results for this study. The quantitative data from the identity measure ISI-6G, PIES fidelity subscale, and GSE are presented showing Cronbach's alphas for all three measures to exhibit internal consistency of the measures. Pearson correlations were used to establish data for the relationships between measures. The findings demonstrate the differences between the means of the pre- and posttest measures by reporting the results from the paired-samples $t$ - test and the statistical details for each test.

\section{Reliability of Measures}

Initial analysis began with determining the internal consistency of the ISI-6G subscales, fidelity subscale, and GSE by performing Cronbach's alphas on both pre- and posttest measures, which are all presented in Table 1. Each measure's results are presented in further detail. The 4subscales of the Berzonsky ISI-6G, information, normative, diffuse, and commitment subscales, were tested for reliability according to internal consistency. Reliability statistics for the 11-item information-orientation subscale (pretest $\alpha=.72$ and posttest $\alpha=.59$ ) are presented in Table 1 and demonstrated internal consistency. The 9-item normative-orientation subscale is presented in Table 2 (pretest $\alpha=.65$ and posttest $\alpha=.64$ ) with data indicating acceptable internal consistency. Cronbach's alpha for the 10 -item diffuse-orientation was (pretest $\alpha=.67$ and posttest $\alpha=.86$ ) and is presented in Table 1. Lastly, the 9-item commitment scale (pretest $\alpha=.65$ and posttest $\alpha=.75$ ) is presented in Table 1. The commitment subscale includes 4-items that are recoded to accurately access responses of participants. The 8-item PIES subscale of Fidelity (pretest $\alpha=.60$ and posttest $\alpha=.74$ ) is presented in Table 1. The 10-item GSE measure (pretest $\alpha=.83$ and posttest $\alpha=.83$ ) is presented in Table 1 . The Cronbach's alphas were acceptable for all measures and 
examination of item-total data revealed that no items needed to be excluded for increased reliability; therefore, further analyses proceeded.

\section{Correlational Analyses}

Pearson correlations were computed to assess the relationship between the measures. These results are presented in Table 2 for pretest and Table 3 for posttest correlations. A significant positive correlation between pretest GSE and pretest fidelity $r=.672, p<.01$ demonstrated that a high score in one variable, self-efficacy, is associated with a high score in the other variable, fidelity, and vice versa. Likewise, there was a significant positive correlation between the pretest fidelity and information subscale $r=.666, \mathrm{p}<.01$. Similarly, there was a significant positive correlation between the normative style of identity and fidelity $r=.557, \mathrm{p}<$ .01 denoting that high scores in normative style are associated with high scores in fidelity. Fidelity and the diffuse identity style $r=-.573, \mathrm{p}<.01$ were found to be positively correlated indicating that high scores in fidelity are associated with lower diffuse scores. Pretest fidelity and the commitment subscales $r=.568, \mathrm{p}<.01$ were significantly positively correlated showing that when someone scores high in fidelity scores in commitment are also high.

Next, pretest GSE was found to be significantly positively correlated with other pretest data for the information subscale $r=.526, \mathrm{p}<.01$, normative subscale $r=.552, \mathrm{p}<.01$, and commitment subscale $r=.551, \mathrm{p}<.01$ indicating that when scores are high in one variable scores in the other variable will be high and vice versa. The GSE scale and the diffuse subscale $r=-.517$, $\mathrm{p}<.01$ were significantly negatively correlated meaning that high self-efficacy scores are associated with lower diffuse scores. Additionally, the pretest information subscale and normative subscale were significantly positively correlated $r=.457, \mathrm{p}<.01$ as well as commitment and normative subscales $r=.498, \mathrm{p}<.01$ indicating that high scores in one variable 
will be paralleled by high scores in the other variable. The diffuse subscale was significantly negatively correlated with information identity style $r=-.448, \mathrm{p}<.01$ demonstrating that high information scores are associated with lower diffuse scores. Finally, the commitment scale was found to be significantly positively correlated with fidelity $r=.568, \mathrm{p}<.01$ and information subscale $r=.588, \mathrm{p}<.01$ indicating that high scores in one variable are associated with high scores in the other variables.

For the posttest scores, GSE and fidelity were significantly correlated $r=.570, \mathrm{p}<.01$ indicating that high self-efficacy and fidelity scores are associated. GSE and information identity style $r=.669, \mathrm{p}<.01$ and commitment $r=.636, \mathrm{p}<.01$ provide support that these constructs have similarities that significantly positively correlate and have higher scores simultaneously. Likewise, GSE and diffuse identity style significantly negatively correlate $-.582, p<.01$ indicating that high self-efficacy scores are associated with lower diffuse scores. Information identity style was found to be significantly positively correlated with commitment $r=.669, \mathrm{p}<$ .01 as well as diffuse identity style $r=-.629, \mathrm{p}<.01$ but note that high information style indicate lower diffuse scores whereas high information and commitment scores are associated. Commitment and the diffuse subscale significantly negatively correlate $r=-.816, \mathrm{p}<.01$ and higher scores in one variable are associated with lower scores in the other variable.

\section{Hypothesis Testing}

Paired-samples $t$-tests were used to determine the mean differences between pre- and posttest scores of the 28 participants. These results are presented in Table 4. An alpha level of .05 was used for all statistical tests. The information subscale pretest $(\mathrm{M}=3.40, \mathrm{SD}=.65)$ and the information subscale posttest $(\mathrm{M}=3.82, \mathrm{SD}=.51)$ both achieved the required significance level, $t(27)=-2.88, p=.008$, to signify an increase in information orientation among participants from 
pretest to posttest thereby supporting hypothesis 1 . The difference between the diffuse subscale pretest $(\mathrm{M}=2.71, \mathrm{SD}=.63)$ and posttest $(\mathrm{M}=2.65, \mathrm{SD}=.86)$ was found to be non-significant, $t(27)=.372, p=.713$, denoting that participants did not have a lower diffuse orientation from pretest to posttest; therefore, hypothesis 2 was refuted. Similarly, the normative subscale pretest $(\mathrm{M}=3.38, \mathrm{SD}=.64)$ and posttest $(\mathrm{M}=3.44, \mathrm{SD}=.10)$ indicated non-significant results, $t(27)=-$ $.476, p=.638$, for lower normative orientation from pretest to posttest thereby not supporting hypothesis 2 . The final subscale of the ISI-6G, commitment orientation pretest $(\mathrm{M}=3.37$, $\mathrm{SD}=.69)$ and posttest $(\mathrm{M}=3.72, \mathrm{SD}=.71)$ indicated participation in the junior volunteer program resulted in a marginally significant increase in commitment $t(27)=-1.98, p=.057$, thereby somewhat confirming hypothesis 3 that commitment would be higher from pretest to posttest.

The fidelity subscale pretest $(\mathrm{M}=3.71, \mathrm{SD}=.65)$ and posttest $(\mathrm{M}=4.04, \mathrm{SD}=.72)$ results indicated an increase in the ego strength of fidelity demonstrating a significant difference between pre- and posttest $t(27)=-.3 .12, p=.004$, thereby confirming hypothesis 4 . The GSE results for the pretest $\mathrm{M}=3.73, \mathrm{SD}=.70)$ and posttest $(\mathrm{M}=4.12, \mathrm{SD}=.63)$ indicated a significant increase, $t(27)=-2.84, p=.008$, in general self-efficacy, signifying that participants did have an increase in self-efficacy pretest to posttest confirming hypothesis 5 . 
Running Head: IDENTITY AND SELF-EFFICACY DEVELOPMENT 38

\section{CHAPTER 5}

\section{DISCUSSION}

The present study aimed to examine the impacts that adult sponsored volunteer programs have on adolescents' identity and self-efficacy. Specifically, the work attempted to determine changes in identity style orientations using the ISI-6G, the ego strength of fidelity using the PIES, and general self-efficacy using the GSE. This study sought to distinguish adult sponsored volunteer programs as a context for positive changes in adolescent identity and self-efficacy.

Support for the findings can be found in the reliability of the measures assuring the researcher that appropriate measures are being used to assess the hypotheses. Subscales from the ISI-6G demonstrated acceptable reliability through Cronbach's alphas test of internal consistency.. The normative pre- and posttest Cronbach's alpha supported internal consistency. Likewise, the diffuse orientation was found to have acceptable Cronbach's alpha for pre- and posttest. Cronbach's alpha for both pre- and posttest commitment subscales reached acceptable internal consistency. Finally, the PIES and GSE were found to have acceptable pre- and posttest reliability.

The findings offer several discussion points. First, Pearson correlations were used to assess the relationship between pre- and posttest measures. The findings found significant correlations between many of the positively perceived variables, including, information, commitment, fidelity, and self-efficacy. This signifies that a high score in one measure is associated with a high score in the other measure and a lower score in one measure is associated with a lower score in the other measure. The more negatively perceived identity orientations, normative and diffuse styles, were found to be significantly negatively correlated with fidelity, self-efficacy, information, and commitment indicating that higher scores in one measure were associated with lower scores in the other measure and vice versa. 
The paired samples $t$-test statistics for the ISI-6G information orientation suggest that adolescents enrolled in an adult sponsored volunteer program increased in their information identity style. This significant finding indicates that participants gained thoughtful insight on their goals and exploration for identity. This is consistent with hypothesis 1 and the prediction that information orientation style would increase from pretest to posttest. The decisional strategies and exposure to alternative values and behaviors consistent with participation in an adult sponsored volunteer are characteristic of developing an informational orientation (Berzonsky \& Ferrari, 2009). Furthermore, this program serves as a socialization agent for the emerging self-concept of adolescents (Erikson, 1950). For example, the participants commonly communicate with staff providing the opportunity for individuals to consider other perspectives leading to a better understanding of their goals and behaviors. Additionally, these youth interact and serve as aides with the younger population attending the program and gain insight into empathy and responsibility thereby promoting reflection which provides a sense of self-meaning (Erikson, 1985). These experiences are representative of the informational style which is often associated with gaining a meaningful sense of self (Berzonsky \& Ferrari, 2009).

Potential problems with identity styles, perceived as less mature development, were found to be non-significant in normative and diffuse orientations. The normative orientation did not reach statistical significance. The normative orientation consists of commitment to goals with out exploration, which is a less desired orientation than information and commitment. The diffuse style is perceived as an unproductive form of identity, defined by impulsiveness and a lack of goals, and is not a desired style of adolescents' identity development. Therefore, hypothesis 2 was not supported because diffuse and normative orientations did not significantly decrease. Berzonsky and Ferrari (2009) provide an explanation for the lack of findings for 
diffuse and normative orientations advising that these identity styles are prone to temporary compliance but seldom exhibit sustained or modified new behaviors. This suggests that perhaps the normative and diffuse orientations are less prone to change or require a more extensive intervention than this program could provide.

Commitment is the dedication to any plans or tasks, which is perceived as a positive attribute of adolescent identity. Additionally, the paired sample $t$-test for pre- and posttest commitment was significant indicating an increase in adolescent's commitment to goals and tasks while participating in an adult sponsored volunteer. The findings support hypothesis 3 that stated, adolescents who participate in an adult sponsored volunteer program will have higher levels of commitment posttest compared to pretest.

The program appears to advance productive identity styles but not diminishing less mature forms of identity. This difference in change may be due to the willingness for maturation possessed by the information identity style and commitment. Information orientation is associated with exploration and the inclination for change while diffuse and avoidant styles possess reluctance for exploring new issues (Youniss et al., 1999). The less mature forms of identity, diffuse and normative, are prone to situation specific decisions that are temporarily relevant and result in short-term adjustments in identity but are not sustained (Berzonsky \& Ferrari, 2009). Overall, the information orientation style and commitment characteristically is more likely to change due to the efforts of exploration (Berzonsky \& Ferrari, 2009).

The fidelity subscale pre- and posttest measures indicated significant findings. In accordance with hypothesis 4 and the achieved results, the ego strength of fidelity increased from pretest to posttest. It can thus be assumed that adolescents' participation in adult sponsored volunteer activities is progressively dedicated to their beliefs and sustaining of these beliefs 
(Erikson \& Erikson, 1982). Fidelity encompasses the dedication to one's beliefs; therefore, the social environment of this program provided opportunities for adolescents to actively display beliefs and receive social and cultural feedback to confirm these beliefs (Erikson, 1985;

Markstrom \& Kalmanir, 2001). Similarly, the ISI-6G commitment subscale, as mentioned above perceives adolescents' ability to evaluate and resolve conflict in identity as a dedication to values, beliefs, and behaviors. Additionally, both are perceived as higher-level identity development relative to commitment. The ego strength of fidelity emerges from previous stages and successful resolution of the identity crisis by connecting past experiences with new concepts (Erikson, 1950). Likewise, commitment progresses as one dedicates themselves to the perceptions gained from past and present exploration. The results indicate that these similar constructs increased pretest to posttest. It also is shown that the fidelity subscale and commitment subscale are significantly correlated as indicated in Table 3showing both scales are measuring similar constructs.

The General Self-Efficacy comparison of pre- and posttest scores exhibited statistically significant findings that support the hypothesis that adolescent's self-efficacy would increase upon completion of the adult sponsored volunteer program. The results signify that adolescents who participate in these programs believe they possess the competency to set and reach goals even when faced with obstacles (Bandura, 2006). There are certain activities that facilitate adolescent self-efficacy development, one being participation in adult sponsored activities (Bandura, 2006). This coincides with the findings of this study and further supports the notion that structured environments provide successful experiences that encourage self-efficacy (Bandura, 1994). 
The findings indicate that it is plausible that adult sponsored volunteer programs support positive identity development and increased self-efficacy. The present research is consistent with previous literature presented in chapter 2. Larson et al. (2006) found adult sponsored volunteer programs to be a context that promoted identity exploration. Likewise, Reimer et al. (2009) found that volunteer commitment was associated with setting personal goals and staying committed to these tasks, which reflects the significant findings of the ISI-6G subscales. Furthermore, Youniss et al. (1999a) reported that the frequency of participation in these programs was a protective factor for increases in normative and diffuse orientations, which were associated with deviant behaviors. The relationship between participation in an adult sponsored volunteer program and identity development was found to be significant in this study as well as previous studies. For example, Markstrom et al. (2005) examined ego strength association with participation in these contexts and found volunteerism to be related to fidelity, which is indicative of identity formation. These studies combined with the recent findings of this study strengthen the association between participation in adult sponsored activities and adolescent's identity formation. Despite the lack of research examining the association between participation and self-efficacy, this study and other research supports that participation in adult sponsored volunteer activities increases self-efficacy. For example, Wood, Larson and Brown (2009) found adult sponsored volunteer activities to be associated with attributes of self-efficacy. The accumulation of past and current research findings in this field of study helps to advance knowledge on this topic. The following explanation provides insight into the contributions from this study.

A large goal of this study was to identify adult sponsored volunteer programs as a context for identity and self-efficacy development. This specification can highlight the distinctive 
qualities and contributions of each program. Furthermore, this research was unique in examining the impact of these programs on both identity development and self-efficacy as associated variables. Bivariate analyses of this study's measures provide support that self-efficacy is significantly correlated with the ego strength of fidelity, information identity style, normative identity style, and commitment. Interestingly, the analysis supports that higher self-efficacy scores are associated with lower diffuse orientation scores. This data is provided in Table 2 and 3. Increases in self-efficacy advance goal setting and exploration for adolescents, which continues identity development and may produce productive and capable youth with the ability to make responsible choices. The social cognitive theory supports this association by theorizing that the inner drive that compels individuals to pursue and commit to goals is self-efficacy, thus becoming a vital precursor for successful identity achievement (Bandura, 1994). It can be suggested with the support of reviewed literature and the presented data that self-efficacy and fidelity are related to one another and both were positively impacted through participation in an adult sponsored volunteer activity.

\section{Contributions}

The primary achievement of this study is that by determining adult sponsored volunteer activities as a context for adolescents' positive development, more evidence is given for the importance of these programs potentially stimulating more program development and opportunities for youth to engage in these programs. The results from this study can be used in grant writing for not only this program but similar programs. Additionally, awareness for the impact of these programs will promote enrollment and resources to enhance and expand programs. The more opportunities and outreach these programs are capable of providing, the more likely that at-risk behaviors and attitudes will decrease and be replaced with positive 
outcomes. This process would likely increase adolescent volunteerism and more youth would gain the developmental benefits. The possibility that adolescents' participation in these programs will lead to positive development and actions is a benefit to not only individuals but to societal structures as well (Cemalcilar, 2009). Most importantly, this study signifies that positive development can be guided in structured programs. For example, the Shack provides qualified and dedicated staff, tasks that require responsibility, skills, and trust, along with the freedom to enjoy their activities. This program provides participants with an optimal context for identity and self-efficacy development, which can be emulated by similar programs to achieve similar results.

An important part of this research is being able to apply proactive methods that will result in positive outcomes for adolescents. Through working with adolescents, this research reiterates the need for adults to foster methods that provide opportunities for youth to gain awareness on new perspectives. The need to support exploration is a vital contribution that practitioners, families, and communities can provide youth. This study confirms a specified context within which adolescents can thrive. The overall benefit of this study is adding to the availability of valid and reliable research that associates adult sponsored volunteer programs, adolescent identity development, and self-efficacy. Further research can strengthen this area of study by examining limitations of the current research.

\section{Limitations}

Although the aim of this research was achieved, there were limitations. First, because of enrollment limits with the junior volunteer program, this study was conducted with a small sample size. A larger sample size would provide stronger statistical power for analyses. Next, the junior volunteer program is unique in experiences, skills, and staff it offers participants, which makes generalizability of the program more of a challenge. Additionally, the limited 
duration of the program makes it difficult to determine if sustainable changes occurred within the participants by posttest collection. This also calls into question the large variability in the number of volunteer hours, ranging from 27 to 240 hours.

\section{Future Research and Conclusion}

This study shows a relationship between participation in adult sponsored volunteer programs and increased levels of identity, fidelity, and self-efficacy. The pre- and posttest data collections produced beneficial findings; the effectiveness of adult sponsored volunteer programs can be better evaluated over a longer time frame. Moreover, a longer program may distinguish factors that promote identity development in the less mature identity styles, diffuse and normative. Additionally, a beneficial direction for future research would be to examine specific variables within the context of an adult sponsored volunteer program that promote or lessen identity development, fidelity, and self-efficacy (i.e. staff, mission and goals of program, activities etc.). Similarly, a more detailed examination of the correlational significance of the measured constructs could determine similarities across constructs that promote positive youth development. There is a strong hope that with the support of this study and past literature, researchers can further yield findings to benefit adolescent research. While the opportunity for future research to fill the gaps of this research is needed, the present study adds to the abundance of research supporting the benefits of adult sponsored volunteer activities, specifically focusing on identity, the ego strength of fidelity and self-efficacy. 


\section{References}

Bandura, A. (2006). Adolescent development from an agentic perspective. In Pajares, F. \& Urdan, T. (Eds.). Self-efficacy beliefs of adolescents, (Vol. 5., pp. 1-43). Greenwich, CT: Information Age Publishing.

Bandura, A. (1994). Self-efficacy. In V. S. Ramachaudran (Ed.), Encyclopedia of human behavior (Vol. 4, pp. 71-81). New York: Academic Press. (Reprinted in H. Friedman (Ed.), Encyclopedia of mental health. San Diego: Academic Press, 1998.

Bandura, A. (1986). Social foundations of thought and action: A social cognitive theory. Englewood Cliffs, NJ: Prentice-Hall.

Bandura, A.(1977). Self-efficacy: Toward a unifying theory of behavioral change, Psychological Review, 84, 191-215.

Berzonsky, M.D. (1989). Identity style: Conceptualization and measurement. Journal of Adolescence Research, 4, 267-281.

Barber, B., Stone, M., Hunt, J., \& Eccles, J. (2005). Benefits of activity participation: The roles of identity affirmation and peer group norm sharing. Organized activities as contexts of development: Extracurricular activities, after-school and community programs (pp. 185210). Mahwah, NJ: Lawrence Erlbaum Associates Publishers.

Benson, P. L., Scales, P. C., Hamilton, S. F., \& Sesma, A. R. (2006). Positive Youth Development: Theory, Research, and Applications. In R. M. Lerner, W. Damon, R. M. Lerner, W. Damon (Eds.), Handbook of child psychology: Theoretical models of human development (pp. 894-941). Hoboken, NJ: John Wiley \& Sons Inc. Retrieved from EBSCOhost. 
Berzonsky, M. D., \& Ferrari, J. R. (2009). A diffuse-avoidant identity processing style: Strategic avoidance or self confusion? Identity: An International Journal of Theory and Research, 9, 145-158.

Centers for Disease Control and Prevention (2009). 2009 Youth Risk Behavior SurveillanceUnited States. Available at: www.cdc.gov/mmwr/pdf/ss/ss5905.pdf. Accessed on January 15, 2011.

Congress of the U.S., (2003). Investment in after-school programs. Hearing before a subcommittee of the committee on appropriations, United States Senate. One Hundred Eighth Congress, First Session, Special Hearing (May 13, 2003). Retrieved from EBSCOhost.

D'Amico, E. J. \& McCarthy, D. M. (2006). Escalation and initiation of younger adolescents' substance use: The impact of perceived peer use. Journal of Adolescent Health, 39, 481487.

Eccles, J.S., \& Barber, B.L. (1999). Student council, volunteering, basketball, or marching band: What kind of extracurricular involvement matters? Journal of Adolescent Research, 14, 10-43.

Eccles, J., Gootman, J., Institute of Medicine (NAS), W. C. (NAS), Washington, DC., \& National Academy of Sciences - National Research Council, W. s. (2002). Community Programs To Promote Youth Development. Retrieved from EBSCOhost.

Eccles, J., Midgley, C., Buchanan, C., Wigfield, A., Reuman, D., MacIver, D. (1993). Development during adolescence: The impact of stage/environment fit on young adolescents' experiences in schools and families. American Psychologist, 48, 90-101. 
Erikson, E. (1988). Youth: Fidelity and diversity. Daedalus, 117, 1-24. Retrieved from PsycINFO database.

Erikson, E. (1985). The Life Cycle Completed. Norton, New York.

Erikson, E. \& Erikson, J. (1982). The Life Cycle Completed. New York: Norton

Erikson, E. H. (1968). Identity: Youth and crisis. New York: Norton.

Erikson, Erik. (1950). Childhood and society. New York: Norton

Grimm, R., Jr., Spring, K., \& Dietz, N. (2007). The health benefits of volunteering: A review of recent research. Washington, DC: The Corporation for National and Community Service, Office of Research and Policy Development.

Hedin, D., \& Conrad, D. (1980). Study roves hypothesis-and more. Synergist, 9. 8-14.

Holden, G. W., Moncher, M. S., Schinke, S. P., \& Barker, K. M. (1990). Self-efficacy of children and adolescents: A meta-analysis. Psychological Reports, 66(3, Pt 1), 10441046. doi:10.2466/PR0.66.3.1044-1046.

Johnson, M. K., Beebe, T., Mortimer, J. T., \& Snyder, M. (1998). Volunteerism in adolescence: A process perspective. Journal of Research on Adolescence, 8, 309-332.

Larson, R. W., Hansen, D. M., \& Moneta, G. (2006). Differing profiles of developmental experiences across types of organized youth activities. Developmental Psychology, 42(5), 849-863. doi:10.1037/0012-1649.42.5.849

Marcia, James. (1991). Identity and self-development. In Lerner, R., Peterson, A., and BrooksGunn, J. (Eds.), Encyclopedia of Adolescence. New York: Garland.

Markstrom, C., Li, X., Blackshire, S., \& Wilfong, J. (2005). Ego strength development of adolescents involved in adult-sponsored structured activities. Journal of Youth and Adolescence, 34(2), 85-95. doi:10.1007/s10964-005-3208-8. 
Markstrom, C., \& Kalmanir, H. (2001). Linkages between the psychosocial stages of identity and intimacy and the ego strengths of fidelity and love. Identity: An International Journal of Theory and Research, 1(2), 179-196. doi:10.1207/S1532706XID0102_05.

Markstrom, C. A., \& Marshall, S. K. (2007). The psychosocial inventory of ego strengths: Examination of theory and psychometric properties. Journal of Adolescence, 30(1), 6379. doi:10.1016/j.adolescence.2005.11.003.

Markstrom, C. A., Sabino, V. M., Turner, B. J., \& Berman, R. C. (1997). The psychosocial inventory of ego strengths: Development and validation of a new Eriksonian measure. Journal of Youth and Adolescence, 26(6), 705-732. doi:10.1023/A:1022348709532.

National Institute on Out-of-School Time. (2008). Making the case: A 2008 fact sheet on children and youth in out-of-school time. Wellesley Centers for Women at Wellesley College.

Pajares, F. (2002). Overview of social cognitive theory and of self-efficacy. Retrieved December3, 2009, from http://www.emory.edu/EDUCATION/mfp/eff.html.

Perkins, D. F., Borden, L. M., \& Villarruel, F. A. (2001). Community youth development: A partnership in action. The School Community Journal, 11(2), 39-56.

Pintrich, P.R. \& De Groot E. (1990). Motivational and self-regulated learning components of classroom academic performance. Journal of Educational Psychology, 82(1), pp. 33-50.

Reimer, K., DeWitt Goudelock, B., \& Walker, L. (2009). Developing conceptions of moral maturity: Traits and identity in adolescent personality. The Journal of Positive Psychology, 4(5), 372-388. doi:10.1080/17439760902992431. 
Ryder, J. A. (2006). College student volunteerism: A quantitative analysis of psychological benefits gained through time spent in service to others. Dissertation Abstracts International Section A, 66, Retrieved from EBSCOhost.

Scanlan, T. K., Babkes, M. L., \& Scanlan, L. A. (2005). Participation in sport: A developmental glimpse at emotion. In J. L. Mahoney, R. W. Larson, J. S. Eccles, J. L. Mahoney, R. W. Larson, J. S. Eccles (Eds.), Organized activities as contexts of development: Extracurricular activities, after-school and community program. (pp. 275-309). Mahwah, NJ US: Lawrence Erlbaum Associates Publishers.

Schwarzer, R., \& Jerusalem, M. (1995). Generalized self-efficacy scale. In J. Weinman, S. Wright, \& M. Johnston, Measures in health psychology: A user's portfolio. Causal and control beliefs (pp. 35-37). Windsor, UK: NFER-NELSON.

U.S. Census Bureau (2010). State \& county quick facts. Available at: http:/quickfacts.census.gov/qfd/states/54/54061.html

West Virginia Kids Counts Data Book: Profiles of Child Well-Being, (2008).

White, J. M., Wampler, R. S., \& Winn, K. I. (1998). The identity style inventory: A revision with a sixth-grade reading level (ISI-6G). Journal of Adolescent Research, 13(2), 223-245. doi: $10.1177 / 0743554898132007$.

Wilson, J.(2000). Volunteering. Annual Review of Sociology, 26, 215-240.

Wood, D., Larson, R. W., \& Brown, J. R. (2009). How adolescents come to see themselves as more responsible through participation in youth programs. Child Development, 80(1), 295-309. doi:10.1111/j.1467-8624.2008.01260.x.

Youniss, J., McLellan., J.A., and Su, Y., and Yates, M. (1999a). The role of community service in identity development: Normative, unconventional, and deviant orientations. 
Journal of Adolescent Research. 14:248-261.

Youniss, J., McLellan, J.A., and Yates, M. (1997). What we know about engendering civic identity. American Behavioral Scientist. 40: 620-631.

Youniss, J., McLellan., J.A., and Su, Y.(1999b). Religion, community service, and identity in American youth. Journal of Adolescent Research.22: 243-253. 


\section{APPENDIX A}

\section{Parental Consent Form}

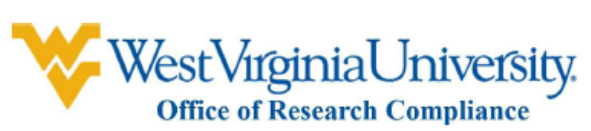

\section{PARENTAL OR GUARDIAN CONSENT AND INFORMATION FORM}

OMR-Parental Consent

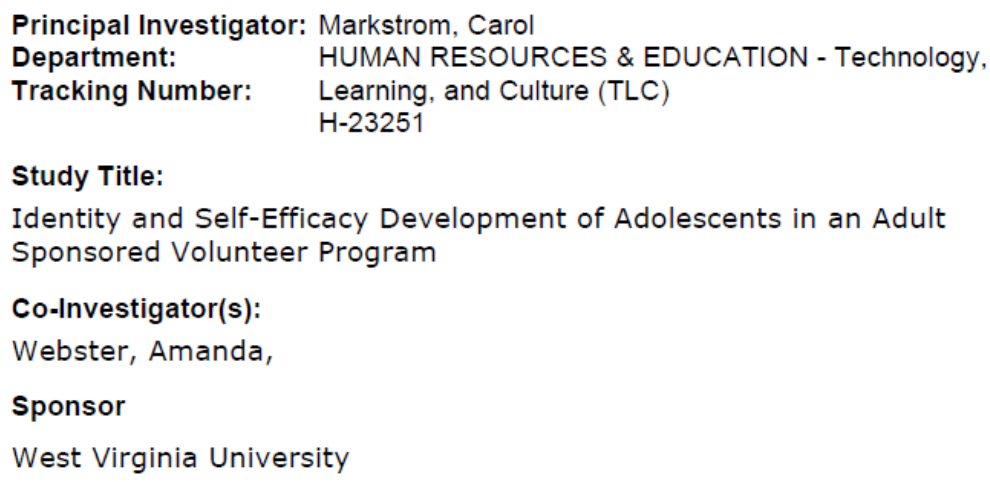




\section{Study Title:}

Identity and Self-Efficacy Development of Adolescents in an Adult Sponsored Volunteer Program

\section{Co-Investigator(s):}

Webster, Amanda,

\section{Sponsor}

West Virginia University

\section{Contact Persons}

If you have any questions, concerns, or complaints about this research, you can contact Dr. Carol Markstrom at 304-293-3344.

For information regarding your rights as a research subject, you may contact the Office of Research Compliance at 304/293-7073.

\section{Introduction}

In addition if you would like to discuss problems, concerns, have suggestions related to research, or would like to offer input about the research, contact the Office of Research Integrity and Compliance at 304293-7073.

You, , have been asked to allow your child to participate in this study, which has been explained

suggestions related to research, or would IIke to orter input about the research, contact the Office of Research Integrity and Compliance at 304293-7073.

You, have been asked to allow your child to participate in this study, which has been explained

\begin{tabular}{lll}
\hline Tracking \#: & $\mathrm{H}-23251$ & Page 1 of 5 \\
Approved On: & $05 / 31 / 2011$ & \\
Valid Through: & $05 / 30 / 2012$ & \\
Last Amended: & N/A &
\end{tabular}

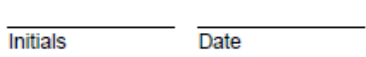

Last Amended: N/A 
Tracking \#: $\quad \mathrm{H}-23251$

to you and your child by

Amanda Webster, B.S. This study is being conducted by Dr. Carol Markstrom Ph.D. and Amanda Webster B.S. in the Department of Technology, Learning and Culture at West Virginia University. This research is being conducted to fulfill the requirements for a master' $s$ thesis in Educational Psychology under the supervision of Dr. Carol Markstrom.

Tracking \#: $\quad \mathrm{H}-23251$

to you and your child by

Amanda Webster, B.S. This study is being conducted by Dr. Carol Markstrom Ph.D. and Amanda Webster B.S. in the Department of Technology, Learning and Culture at West Virginia University. This research is being conducted to fulfill the requirements for a master's thesis in Educational Psychology under the supervision of Dr. Carol Markstrom.

\section{Purposes of the Study}

The purpose of this study is to learn more about participation in an adult sponsored volunteer program and the developmental outcomes of identity, the ego strength of fidelity, and self-efficacy. WVU expects to enroll approximately 40 subjects

\section{Description of Procedures}

This study involves completing four surveys for your child to complete. Your child will be asked to fill out 4 questionnaires regarding background, identity, and self-efficacy. These will be administered twice, once in June and once in August and take a total of 40 minutes. One measure on identity will examine experiences, values, behaviors, and ethics that guide a person's daily activities. More specific, the ego strength of fidelity will look at a your child's dedication to their values, beliefs, and behaviors. 


\section{Purposes of the Study}

The purpose of this study is to learn more about participation in an adult sponsored volunteer program and the developmental outcomes of identity, the ego strength of fidelity, and self-efficacy. WVU expects to enroll approximately 40 subjects

\section{Description of Procedures}

This study involves completing four surveys for your child to complete. Your child will be asked to fill out 4 questionnaires regarding background, identity, and self-efficacy. These will be administered twice, once in June and once in August and take a total of 40 minutes. One measure on identity will examine experiences, values, behaviors, and ethics that guide a person's daily activities. More specific, the ego strength of fidelity will look at a your child's dedication to their values, beliefs, and behaviors. Finally, self-efficacy looks at one's belief that they can reach their goals. This will take approximately $15-20$ minutes to complete. Your child does not have to answer all the questions. You will have the opportunity to see the questionnaire before signing this consent form. A pre-test will be given in June and a post-test in August. The pre- and posttest measures will take a combined total of 40 minutes to complete.

The study will be performed at The Shack Neighborhood House. Approximately 40 subjects are expected to participate in this study.

\section{Risks and Discomforts}

There are no known or expected risks to your child from participating in this study, except for the mild frustration associated with answering the a.........

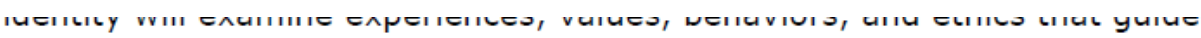
a person's daily activities. More specific, the ego strength of fidelity will look at a your child's dedication to their values, beliefs, and behaviors. Finally, self-efficacy looks at one's belief that they can reach their goals. This will take approximately 15-20 minutes to complete. Your child does not have to answer all the questions. You will have the opportunity to see the questionnaire before signing this consent form. A pre-test will be given in June and a post-test in August. The pre- and posttest measures will take a combined total of 40 minutes to complete.

The study will be performed at The Shack Neighborhood House. Approximately 40 subjects are expected to participate in this study.

\section{Risks and Discomforts}

There are no known or expected risks to your child from participating in this study, except for the mild frustration associated with answering the questions.

\begin{tabular}{lll}
\hline Tracking \#: & $\mathrm{H}-23251$ & Page 2 of 5 \\
Approved On: & $05 / 31 / 2011$ & \\
Valid Through: & $05 / 30 / 2012$ & \\
Last Amended: & N/A &
\end{tabular}




Tracking: $\mathrm{H}-23251$
Alternatives
Your child does not have to participate in this study.
Alternatives that could be considered in your child's case include not
participating in the study.

\section{Benefits}

Your child may not receive any direct benefit from this study. The knowledge gained from this study may eventually benefit others.

\section{Financial Considerations}

No payments will be made for participating in the study.

\section{Confidentiality}

Any information about your child that is obtained as a result of participation in this research will be kept as confidential as legally possible.

Voluntary Particination

\section{Alternatives}

Your child does not have to participate in this study.

Alternatives that could be considered in your child's case include not participating in the study.

\section{Benefits}

Your child may not receive any direct benefit from this study. The knowledge gained from this study may eventually benefit others.

\section{Financial Considerations}

No payments will be made for participating in the study.

\section{Confidentiality}

Any information about your child that is obtained as a result of participation in this research will be kept as confidential as legally possible.

\section{Voluntary Participation}

Participation in this study is voluntary.

You or your child may refuse to participate in this study. You or your child may withdraw from this study at any time.

Refusal to participate or withdrawal will not affect your child's future care or enrollment in the junior volunteer program, and will involve no penalty to you or your child.

In the event new information becomes available that may affect your 
whether or not to continue your child's participation.

You have been given the opportunity to ask questions about the research, and have received answers concerning areas you did not understand.

Tracking \#: $\quad \mathrm{H}-23251$

Approved On: $\quad$ 05/31/2011

Valid Through: 05/30/2012

Page 3 of 5

Last Amended: N/A

Tracking \#: $\quad \mathrm{H}-23251$

Signature of Person 


\section{Appendix B}

\section{Participation Assent Form}

\section{W WestVirginiaUniversity. \\ Office of Research Compliance}

OMR-Assent

Principal Investigator: Markstrom, Carol

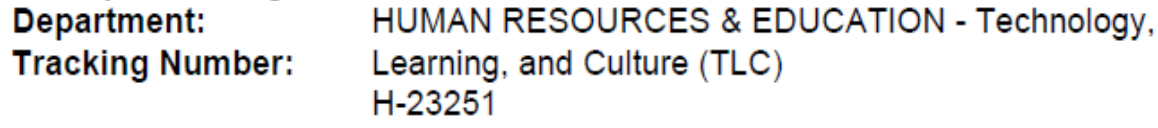

Study Title:

Identity and Self-Efficacy Development of Adolescents in an Adult Sponsored Volunteer Program

Co-Investigator(s):

Webster, Amanda

Sponsor

West Virginia University

\section{Contact Persons}

If you have any questions, concerns, or complaints about this research, you can contact Dr.Carol Markstrom at 304-293-3344 or Amanda Webster, B.S. 304-702-0672.

For information regarding your rights as a research subject, you may contact the Office of Research Compliance at 304/293-7073.

Introduction

In addition if you would like to discuss problems, concerns, have suncestions related to research. or would like to offer innut ahout the 
West Virginia University

\section{Contact Persons}

If you have any questions, concerns, or complaints about this research, you can contact Dr.Carol Markstrom at 304-293-3344 or Amanda Webster, B.S. 304-702-0672.

For information regarding your rights as a research subject, you may contact the Office of Research Compliance at 304/293-7073.

Introduction

In addition if you would like to discuss problems, concerns, have suggestions related to research, or would like to offer input about the research, contact the Office of Research Integrity and Compliance at 304293-7073.You, , have been asked to be in this research study, which has been explained to you by Amanda Webster.

Purposes of the Study

\begin{tabular}{lllll}
\hline Tracking \#: & $\mathrm{H}-23251$ & Page 1 of 4 & \\
Approved On: & $05 / 31 / 2011$ & & Initials & \\
Valid Through: & $05 / 30 / 2012$ & & \\
Last Amended: & N/A & &
\end{tabular}

Tracking \#: $\quad \mathrm{H}-23251$

You have been told that the purpose of this study is to learn more about the outcomes of participation in the Shack's junior volunteer program. The purpose is tto look at the outcomes of identity and self-efficacy development.

\section{Description of Procedures}

This study will be done at The Shack Neighborhood House. After the study is explained you will be asked to fill out a form that says you agree to participate. Participation is strictly voluntary. You will be asked to complete four short surveys during your afternoon meeting the first week of camp. The first is on your background (age, grade etc.) One measure on identity will examine experiences, values, behaviors, and ethics that guide your daily activities. Next and more specific, the ego strength of fidelity will look at a your dedication to your values, beliefs, and behaviors. Finally, selfefficacy looks at your belief that you can reach your goals. The surveys will take 15-20 minutes to complete. You will participate in the junior volunteer program as usual. The last week of the program you will be asked to fill out three of the surveys which will take about 15 minutes. If 
the outcomes of participation in the Shack's junior volunteer program. The purpose is tto look at the outcomes of identity and self-efficacy development.

\section{Description of Procedures}

This study will be done at The Shack Neighborhood House. After the study is explained you will be asked to fill out a form that says you agree to participate. Participation is strictly voluntary. You will be asked to complete four short surveys during your afternoon meeting the first week of camp. The first is on your background (age, grade etc.) One measure on identity will examine experiences, values, behaviors, and ethics that guide your daily activities. Next and more specific, the ego strength of fidelity will look at a your dedication to your values, beliefs, and behaviors. Finally, selfefficacy looks at your belief that you can reach your goals. The surveys will take 15-20 minutes to complete. You will participate in the junior volunteer program as usual. The last week of the program you will be asked to fill out three of the surveys which will take about 15 minutes. If you choose you will complete measures once in June and again in August which will take a total of 40 minutes. You may see the questions before signing this page. You do not have to answer all of the questions. This study is confidential and no one will know your responses because surveys will be identified with an assigned number. Finally, you have the option to stop participation in this study at any time with no problems from the researcher or junior volunteer program.

\section{Discomforts}

You should not experience any discomforts from completing the surveys. 


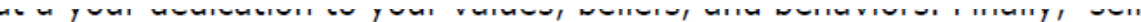

efficacy looks at your belief that you can reach your goals. The surveys will take 15-20 minutes to complete. You will participate in the junior volunteer program as usual. The last week of the program you will be asked to fill out three of the surveys which will take about 15 minutes. If you choose you will complete measures once in June and again in August which will take a total of 40 minutes. You may see the questions before signing this page. You do not have to answer all of the questions. This study is confidential and no one will know your responses because surveys will be identified with an assigned number. Finally, you have the option to stop participation in this study at any time with no problems from the researcher or junior volunteer program.

\section{Discomforts}

You should not experience any discomforts from completing the surveys.

\section{Benefits}

This study may not help you, but what they learn from the study may help other people.

\section{Confidentiality}

You will not identify yourself on the surveys and your responses will not be shared with anyone else and will only be used for this study.

\begin{tabular}{lllll}
\hline Tracking \#: & $\mathrm{H}-23251$ & Page 2 of 4 & \\
Approved On: & $05 / 31 / 2011$ & & Initials & Date \\
Valid Through: & $05 / 30 / 2012$ & &
\end{tabular}

Tracking \#: $\quad$ H-23251

Voluntary Participation

You do not have to do this. No one will be mad at you if you refuse to do this or if you decide to quit. You have been allowed to ask questions about the research, and all of your questions were answered. 
Tracking \#: $\quad \mathrm{H}-23251$

I willingly agree to be in this research.

Signature of Subject

Printed Name

Date

Time

The child has had the opportunity to have questions addressed. The child willingly agrees to be in the study.

Signature of Investigator or

Printed Name

Date

Time

Co-Investigator

\begin{tabular}{lll}
\hline Tracking \#: & H-23251 & Page 4 of 4 \\
Approved On: & $05 / 31 / 2011$ & \\
Valid Through: & $05 / 30 / 2012$ & \\
Last Amended: & N/A &
\end{tabular}

$\overline{\text { Initials }} \overline{\text { Date }}$




\section{Appendix C}

\section{DEMOGRAPHIC}

Please circle the answer that best applies to you. The questions asked are only for purposes of this study and will not be shared with others. Please do not put your name on this survey.

1. What is your age?

12

13

14

15

16

17

18

2. What grade did you just complete?

7

8

9

10

11

12

3. What is your sex?

Female

Male 


\section{APPENDIX D}

\section{IDENTITY STYLE INVENTORY (ISI-6G)}

\section{(Revised Version)}

Michael D. Berzonsky

Department of Psychology

State University of New York at Cortland

Cortland, New York 13045 


\section{PERSONAL SIMILARITIES}

\section{$\underline{\text { INSTRUCTIONS }}$}

You will find a number of statements about beliefs, attitudes, and/or ways of dealing with issues. Read each carefully, then use it to describe yourself. On the answer sheet, bubble in the number which indicates the extent to which you think the statement represents you. There are no right or wrong answers. For instance, if the statement is very much like you, mark a 5, if it is not like you at all, mark a 1 . Use the 1 to 5 point scale to indicate the degree to which you think each statement is uncharacteristic (1) or characteristic (5) of yourself. Regarding religious beliefs, I know basically what I believe and don't believe. (COMM)

1.I've spent a great deal of time thinking seriously about what I should do with my life.

$\begin{array}{lllllll}\text { (NOT AT ALL LIKE ME) } & 1 & 2 & 3 & 4 & 5 & \text { (VERY MUCH LIKE ME) }\end{array}$

2.I'm not really sure what I'm doing in school; I guess things will work themselves out.

$\begin{array}{lllllll}\text { (NOT AT ALL LIKE ME) } & 1 & 2 & 3 & 4 & 5 & \text { (VERY MUCH LIKE ME) }\end{array}$

3.I've more-or-less always followed the values with which I was brought up.

$\begin{array}{lllllll}\text { (NOT AT ALL LIKE ME) } & 1 & 2 & 3 & 4 & 5 & \text { (VERY MUCH LIKE ME) }\end{array}$

4.I've spent a good deal of time reading and talking to others about religious ideas.

$\begin{array}{lllllll}\text { (NOT AT ALL LIKE ME) } & 1 & 2 & 3 & 4 & 5 & \text { (VERY MUCH LIKE ME) }\end{array}$

5.When I discuss an issue with someone, I try to assume their point of view and see the problem from their perspective.

$\begin{array}{lllllll}\text { (NOT AT ALL LIKE ME) } & 1 & 2 & 3 & 4 & 5 & \text { (VERY MUCH LIKE ME) }\end{array}$


6.I know what I want to do with my future.

$\begin{array}{lllllll}\text { (NOT AT ALL LIKE ME) } & 1 & 2 & 3 & 4 & 5 & \text { (VERY MUCH LIKE ME) }\end{array}$

7.It doesn't pay to worry about values in advance; I decide things as they happen.

$\begin{array}{lllllll}\text { (NOT AT ALL LIKE ME) } & 1 & 2 & 3 & 4 & 5 & \text { (VERY MUCH LIKE ME) }\end{array}$

8.I'm not really sure what I believe about religion.

$\begin{array}{lllllll}(\text { NOT AT ALL LIKE ME) } & 1 & 2 & 3 & 4 & 5 & \text { (VERY MUCH LIKE ME) }\end{array}$

9.I've always had purpose in my life; I was brought up to know what to strive for.

$\begin{array}{lllllll}\text { (NOT AT ALL LIKE ME) } & 1 & 2 & 3 & 4 & 5 & \text { (VERY MUCH LIKE ME) }\end{array}$

10.I'm not sure which values I really hold.

$\begin{array}{lllllll}\text { (NOT AT ALL LIKE ME) } & 1 & 2 & 3 & 4 & 5 & \text { (VERY MUCH LIKE ME) }\end{array}$

11.I have some consistent political views; I have a definite stand on where the government and country should be headed.

$\begin{array}{lllllll}\text { (NOT AT ALL LIKE ME) } & 1 & 2 & 3 & 4 & 5 & \text { (VERY MUCH LIKE ME) }\end{array}$

12.Many times by not concerning myself with personal problems, they work themselves out.

$\begin{array}{lllllll}\text { (NOT AT ALL LIKE ME) } & 1 & 2 & 3 & 4 & 5 & \text { (VERY MUCH LIKE ME) }\end{array}$


13.I'm not sure what I want to do in the future.

$\begin{array}{lllllll}\text { (NOT AT ALL LIKE ME) } & 1 & 2 & 3 & 4 & 5 & \text { (VERY MUCH LIKE ME) }\end{array}$

14.I've spent a lot of time reading and trying to make some sense out of political issues.

$\begin{array}{lllllll}\text { (NOT AT ALL LIKE ME) } & 1 & 2 & 3 & 4 & 5 & \text { (VERY MUCH LIKE ME) }\end{array}$

15. I am interested in an academic area or an area of study that is right for me.

$\begin{array}{lllllll}\text { (NOT AT ALL LIKE ME) } & 1 & 2 & 3 & 4 & 5 & \text { (VERY MUCH LIKE ME) }\end{array}$

16.I'm not really thinking about my future now; it's still a long way off. $\begin{array}{lllllll}\text { (NOT AT ALL LIKE ME) } & 1 & 2 & 3 & 4 & 5 & \text { (VERY MUCH LIKE ME) }\end{array}$

17.I've spent a lot of time and talked to a lot of people trying to develop a set of values that make sense to me.

$\begin{array}{lllllll}\text { (NOT AT ALL LIKE ME) } & 1 & 2 & 3 & 4 & 5 & \text { (VERY MUCH LIKE ME) }\end{array}$

18. Regarding religion, I've always known what I believe and don't believe; I never really had any serious doubts.

$\begin{array}{lllllll}\text { (NOT AT ALL LIKE ME) } & 1 & 2 & 3 & 4 & 5 & \text { (VERY MUCH LIKE ME) }\end{array}$

19.I am not sure what I want to study in college, trade school, or higher education.

$\begin{array}{lllllll}\text { (NOT AT ALL LIKE ME) } & 1 & 2 & 3 & 4 & 5 & \text { (VERY MUCH LIKE ME) }\end{array}$


20.I know that after high school I want to go to college, trade school, or higher education.

$\begin{array}{lllllll}\text { (NOT AT ALL LIKE ME) } & 1 & 2 & 3 & 4 & 5 & \text { (VERY MUCH LIKE ME) }\end{array}$

21.I have a definite set of values that I use in order to make personal decisions.

$\begin{array}{lllllll}\text { (NOT AT ALL LIKE ME) } & 1 & 2 & 3 & 4 & 5 & \text { (VERY MUCH LIKE ME) }\end{array}$

22.I think it's better to have a firm set of beliefs than to be open minded.

$\begin{array}{lllllll}\text { (NOT AT ALL LIKE ME) } & 1 & 2 & 3 & 4 & 5 & \text { (VERY MUCH LIKE ME) }\end{array}$

23. When I have to make a decision, I try to wait as long as possible in order to see what will happen. $\begin{array}{lllllll}\text { (NOT AT ALL LIKE ME) } & 1 & 2 & 3 & 4 & 5 & \text { (VERY MUCH LIKE ME) }\end{array}$

24. When I have a personal problem, I try to analyze the situation in order to understand it. $\begin{array}{lllllll}\text { (NOT AT ALL LIKE ME) } & 1 & 2 & 3 & 4 & 5 & \text { (VERY MUCH LIKE ME) }\end{array}$

25.I find it's best to seek out advice from professionals (e.g., Shack staff, clergy, counselors) when I have problems.

$\begin{array}{lllllll}\text { (NOT AT ALL LIKE ME) } & 1 & 2 & 3 & 4 & 5 & \text { (VERY MUCH LIKE ME) }\end{array}$

26.It's best for me not to take life too seriously; I just try to enjoy it.

$\begin{array}{lllllll}\text { (NOT AT ALL LIKE ME) } & 1 & 2 & 3 & 4 & 5 & \text { (VERY MUCH LIKE ME) }\end{array}$

27. I think it's better to have fixed values, than to consider alternative value systems. 
$\begin{array}{lllllll}\text { (NOT AT ALL LIKE ME) } & 1 & 2 & 3 & 4 & 5 & \text { (VERY MUCH LIKE ME) }\end{array}$

28.I try not to think about or deal with problems as long as I can.

$\begin{array}{lllllll}\text { (NOT AT ALL LIKE ME) } & 1 & 2 & 3 & 4 & 5 & \text { (VERY MUCH LIKE ME) }\end{array}$

29.I find that personal problems often turn out to be interesting challenges.

$\begin{array}{lllllll}\text { (NOT AT ALL LIKE ME) } & 1 & 2 & 3 & 4 & 5 & \text { (VERY MUCH LIKE ME) }\end{array}$

30.I try to avoid personal situations that will require me to think a lot and deal with them on my own.
(NOT AT ALL LIKE ME)
1
$2 \quad 3 \quad 4$
5 (VERY MUCH LIKE ME)

31. Once I know the correct way to handle a problem, I prefer to stick with it.

$\begin{array}{lllllll}(\text { NOT AT ALL LIKE ME) } & 1 & 2 & 3 & 4 & 5 & \text { (VERY MUCH LIKE ME) }\end{array}$

32. When I have to make a decision, I like to spend a lot of time thinking about my options.

$\begin{array}{lllllll}\text { (NOT AT ALL LIKE ME) } & 1 & 2 & 3 & 4 & 5 & \text { (VERY MUCH LIKE ME) }\end{array}$

33.I prefer to deal with situations where I can rely on social norms and standards.

$\begin{array}{lllllll}\text { (NOT AT ALL LIKE ME) } & 1 & 2 & 3 & 4 & 5 & \text { (VERY MUCH LIKE ME) }\end{array}$

34.I like to have the responsibility for handling problems in my life that require me to think on my own.

$\begin{array}{lllllll}\text { (NOT AT ALL LIKE ME) } & 1 & 2 & 3 & 4 & 5 & \text { (VERY MUCH LIKE ME) }\end{array}$ 
35.Sometimes I refuse to believe a problem will happen, and things manage to work themselves out. $\begin{array}{lllllll}\text { (NOT AT ALL LIKE ME) } & 1 & 2 & 3 & 4 & 5 & \text { (VERY MUCH LIKE ME) }\end{array}$

36. When making important decisions I like to have as much information as possible.

$\begin{array}{lllllll}\text { (NOT AT ALL LIKE ME) } & 1 & 2 & 3 & 4 & 5 & \text { (VERY MUCH LIKE ME) }\end{array}$

37. When I know a situation is going to cause me stress, I try to avoid it.

$\begin{array}{lllllll}\text { (NOT AT ALL LIKE ME) } & 1 & 2 & 3 & 4 & 5 & \text { (VERY MUCH LIKE ME) }\end{array}$

38.To live a complete life, I think people need to get emotionally involved and commit themselves to specific values and ideals.

$\begin{array}{lllllll}\text { (NOT AT ALL LIKE ME) } & 1 & 2 & 3 & 4 & 5 & \text { (VERY MUCH LIKE ME) }\end{array}$

39.I find it's best for me to rely on the advice of close friends or relatives when I have a problem.

$\begin{array}{lllllll}(\text { NOT AT ALL LIKE ME) } & 1 & 2 & 3 & 4 & 5 & \text { (VERY MUCH LIKE ME) }\end{array}$ 
Directions:

\section{APPENDIX E}

\section{Psychosocial Inventory of Ego Strength (PIES)}

Read each item carefully and consider the degree to which it describes you.

Write the number signifying your response on the line next to each item.

5

Describes me

very well
$4 \quad 3$

32

2

1

Does not describe me well

1. I prefer to be free-floating without having to worry about commitments to other people or things.

2. I find that my opinions are frequently influenced by others.

3. When I make a commitment to something, I stick with it.

4. I don't pretend to be something that I'm not.

5. I believe in being true to myself and others.

6. I'm not really sure what I believe in.

7. I have trouble accepting a particular purpose or role in life.

8. I stand up for the people and causes that are important to me. 


\section{APPENDIX F}

\section{General Self-Efficacy Scale (GSE)}

Directions:

Read each item carefully and consider the degree to which it describes you. Write the number signifying your response on the line next to each item.

$1=$ Not at all true $2=$ Hardly true $3=$ Moderately true $4=$ Exactly true 1. I can always manage to solve difficult problems if I try hard enough.

2.If someone opposes me, I can find the means and ways to get what I want.

3.It is easy for me to stick to my aims and accomplish my goals.

4.I am confident that I could deal efficiently with unexpected events.

5.Thanks to my resourcefulness, I know how to handle unforeseen situations.

6.I can solve most problems if I invest the necessary effort.

7.I can remain calm when facing difficulties because I can rely on my coping abilities.

8.When I am confronted with a problem, I can usually find several solutions.

9.If I am in trouble, I can usually think of a solution.

10.I can usually handle whatever comes my way. 
Running head: IDENTITY AND SELF-EFFICACY DEVELOPMENT

Table 1

Cronbach's alphas for ISI-6G subscales, PIES fidelity subscale, and GSE

\begin{tabular}{|c|c|c|c|}
\hline & $\begin{array}{c}\text { Prettest } \\
\text { Cronbach'sAlpha }\end{array}$ & $\begin{array}{c}\text { Posttest } \\
\text { Cronbach's Alpha }\end{array}$ & $\mathrm{N}$ of Items \\
\hline Information- & .725 & .593 & 11 \\
\hline \multicolumn{4}{|l|}{ Orientation } \\
\hline Normative- & .651 & .664 & 9 \\
\hline \multicolumn{4}{|l|}{ Orientation } \\
\hline Diffuse-Orientation & .671 & .869 & 10 \\
\hline Commitment & .652 & .753 & 9 \\
\hline PIES- Fidelity & .601 & .740 & 8 \\
\hline GSE & .838 & .836 & 10 \\
\hline
\end{tabular}


Table 2

Summary of Posttest Intercorrelations of Measures

\begin{tabular}{lllllll}
\hline Measure & 1 & 2 & 3 & 4 & 5 & 6 \\
\hline & & & & & \\
1. PIES & - & & & & \\
2. GSE & $.57^{* *}$ & - & & & & \\
3. INFO & .36 & $.66^{* *}$ & - & & & \\
4. NORM & .27 & .02 & -.15 & - & & \\
5. DIFFUSE & -.298 & $-.58^{* *}$ & $-.62^{* *}$ & .32 & - & \\
6. COMMIT & .36 & $.63^{* *}$ & $.66^{* *}$ & -.22 & $-.81^{* *}$ & -
\end{tabular}




\section{Table 3}

Summary of Pretest Intercorrelations of Measure

\begin{tabular}{lllllll}
\hline Measure & 1 & 2 & 3 & 4 & 5 & 6 \\
\hline & & & & & & \\
1. PIES & - & & & & \\
2. GSE & $.67^{* *}$ & - & & & & \\
3. INFO & $.66^{* *}$ & $.52^{* *}$ & - & & & \\
4. NORM & $.55^{* *}$ & $.55^{* *}$ & $.45^{*}$ & - & & \\
5. DIFFUSE & $-.57^{*}$ & $-.51^{* *}$ & $-.44^{*}$ & -.03 & - & \\
6. COMMIT & $.56^{* *}$ & $.55^{* *}$ & $.58^{* *}$ & $.49 *$ & -.20 & -
\end{tabular}


Table 4

T-tests, Means, and Standard Deviation Statistics

\begin{tabular}{|c|c|c|c|c|c|}
\hline & M & SD & $\mathrm{T}$ & df & Sig. \\
\hline \multirow[t]{2}{*}{$\begin{array}{l}\text { Information } \\
\text { Prettest }\end{array}$} & 3.4026 & .65715 & & & \\
\hline & & & -2.885 & 27 & .008 \\
\hline $\begin{array}{l}\text { Information } \\
\text { Posttest }\end{array}$ & 3.8279 & .51802 & & & \\
\hline \multirow[t]{2}{*}{ Diffuse Prettest } & 2.7179 & .63832 & & & \\
\hline & & & .372 & 27 & .713 \\
\hline $\begin{array}{l}\text { Diffuse } \\
\text { Posttest }\end{array}$ & 2.6571 & .86557 & & & \\
\hline \multirow[t]{2}{*}{$\begin{array}{l}\text { Normative } \\
\text { Prettest }\end{array}$} & 3.3849 & .64540 & & & \\
\hline & & & -.476 & 27 & .638 \\
\hline $\begin{array}{l}\text { Normative } \\
\text { Posttest }\end{array}$ & 3.4405 & .56614 & & & \\
\hline \multirow[t]{2}{*}{$\begin{array}{l}\text { Commitment } \\
\text { Prettest }\end{array}$} & 3.3770 & .69114 & & & \\
\hline & & & -1.985 & 27 & .057 \\
\hline $\begin{array}{l}\text { Commitment } \\
\text { Posttest }\end{array}$ & 3.7262 & .71529 & & & \\
\hline \multirow[t]{2}{*}{$\begin{array}{l}\text { PIES Fidelity } \\
\text { Prettest }\end{array}$} & 3.714 & .655 & & & \\
\hline & & & -3.126 & 27 & .004 \\
\hline $\begin{array}{l}\text { PIES Fidelity } \\
\text { Posttest }\end{array}$ & 4.044 & .720 & & & \\
\hline \multirow[t]{2}{*}{ GSE Prettest } & 3.739 & .707 & & & \\
\hline & & & -2.845 & 27 & .008 \\
\hline GSE Posttest & 4.12 & .634 & & & \\
\hline
\end{tabular}

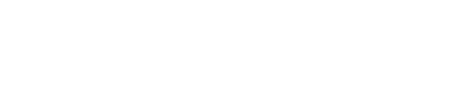

